\title{
Nanotechnology Inspired Tools for Mitochondrial Dysfunction Related Diseases
}

Ru Wen, ${ }^{a}$ Bhabatosh Banik, ${ }^{a}$ Rakesh K. Pathak, ${ }^{a}$ Anil Kumar, ${ }^{a}$ Nagesh Kolishetti, ${ }^{a, b}$ and Shanta Dhar*a

${ }^{a}$ NanoTherapeutics Research Laboratory, Department of Chemistry, University of Georgia, Athens, GA 30602, ${ }^{b}$ Partikula LLC, Sunrise, FL 33326

*To whom correspondence should be addressed.

E-mail: shanta@uga.edu

Shanta Dhar

NanoTherapeutics Research Laboratory

Department of Chemistry

University of Georgia, Athens, GA 30602

Telephone: 706-542-1012

Fax: 706-542-9454

shanta@uga.edu 


\section{Abstract}

Mitochondrial dysfunctions are recognized as major factors for various diseases including cancer, cardiovascular diseases, diabetes, neurological disorders, and a group of diseases so called "mitochondrial dysfunction related diseases". One of the major hurdles to gain therapeutic efficiency in diseases where the targets are located in the mitochondria is the accessibility of the targets in this compartmentalized organelle that imposes barriers towards internalization of ions and molecules. Over the time, different tools and techniques were developed to improve therapeutic index for mitochondria acting drugs. Nanotechnology has unfolded as one of the logical and encouraging tools for delivery of therapeutics in controlled and targeted manner simultaneously reducing side effects from drug overdose. Tailor-made nanomedicine based therapeutics can be an excellent tool in the toolbox for diseases associated with mitochondrial dysfunctions. In this review, we present an extensive coverage of possible therapeutic targets in different compartments of mitochondria for cancer, cardiovascular, and mitochondrial dysfunction related diseases. 


\section{Contents}

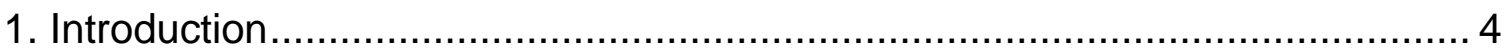

2. Mitochondrial Targets for Cancer .......................................................... 6

2.1. Targets for cancer in the OMM ....................................................... 9

2.2. Targets for Cancer in the IMM and MM ........................................... 12

3. Mitochondrial Targets for Cardiovascular Diseases (CVD) .......................... 24

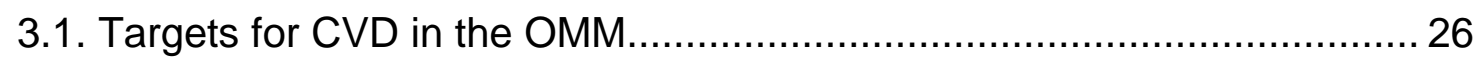

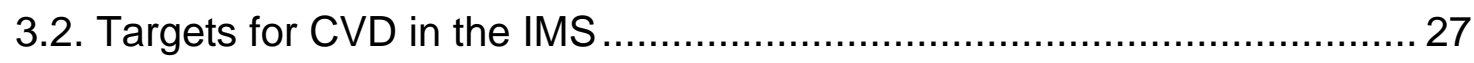

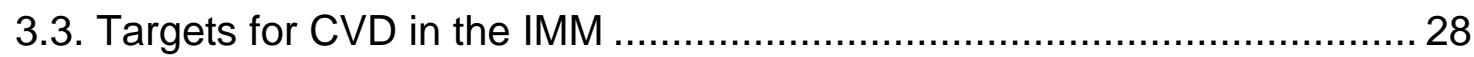

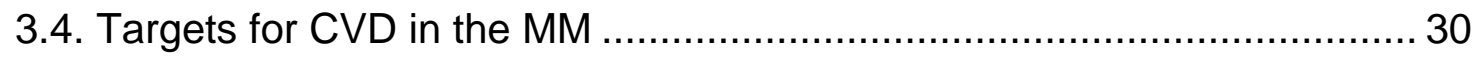

4. Mitochondrial Targets for Mitochondrial Dysfunction Related Diseases ......... 32

4.1. Autism Spectrum Disorders …....................................................... 32

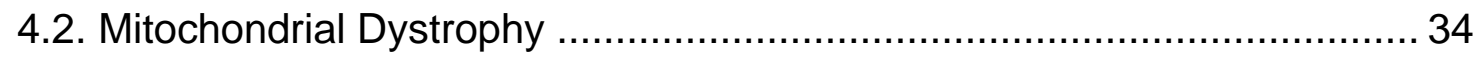

4.3 Mitochondrial Dysfunctions in Epilepsy ……......................................... 35

4.4. Amyotrophic Lateral Sclerosis ............................................

5. Mitochondrial Targets for Neurological Diseases ...................................... 38

6. Mitochondrial Nanomedicine: The Future .................................................. 40

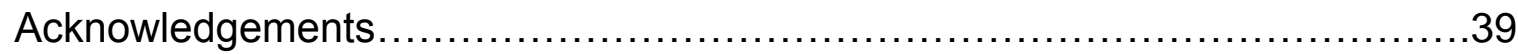

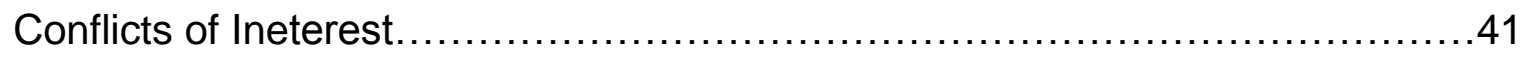

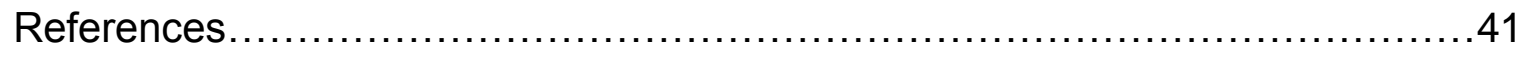




\section{Introduction}

Mitochondria are recognized as the most intriguing energy producing organelle of the eukaryotic cells, which produce adenosine triphosphate (ATP) via oxidative phosphorylation (OXPHOS) (1-3). The name mitochondrion was derived from two Greek words "mitos" for "thread" and "chondrion" for "granule" (2). The complex structural morphology of mitochondria was first visualized in 1952 by high resolution electron microscopy studies (4). In addition to participation in OXPHOS, these organelles store various ions and proteins to manage oxidative stress and cell mortality. Mitochondrial DNA (mtDNA) built of 16569 base pairs encode for various proteins, RNAs, and the close proximity to the reactive oxygen species (ROS) make these genome highly susceptible to mutations in comparison to extent of mutations found in the nuclear DNA (nDNA). In addition to the complex structure, mitochondrial network also maintains high levels of dynamic processes to keep the balance between fusion and fission processes. Another layer of complexity is added on these organelles due to the presence of unusual phospholipid cardiolipin $(\mathrm{CL})$, which contributes largely for the array of mitochondrial processes. Thus, this closed packed complex yet dynamic mitochondria maintain cellular mortality events by controlling vital cellular reactions, such as, energy production, redox balance, $\mathrm{Ca}^{2+}$ levels, initiation of apoptosis, and homeostasis of biomolecules in the cytosol. Even minor modifications of any of these parameters can disrupt cellular processes causing mitochondrial dysfunction and excessive mutation of mtDNA brings additional possibility of multiple mitochondrial diseases (5). A list of mitochondrial dysfunction related diseases are depicted in Figure 1. Thus, therapeutic modulation by attacking different mitochondrial targets can provide better management of diseases where mitochondrial dysfunctions are involved (6). However, the complex structure of the mitochondria designed by the nature to maintain important cellular functions imposes 
quite a challenge to engineer technologies which can navigate to this organelle for accessing different targets.

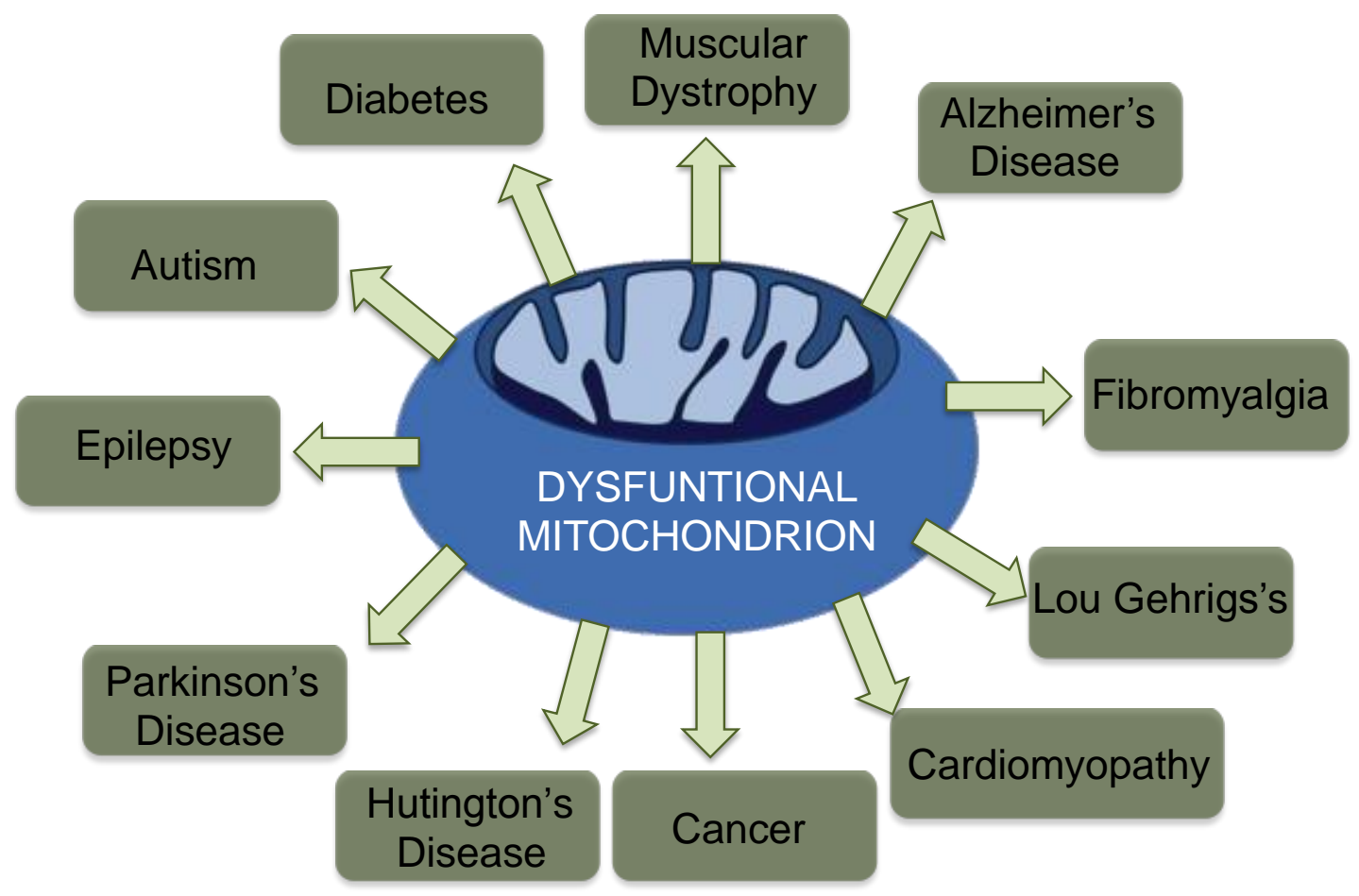

Figure 1. Contribution of mitochondrial dysfunctions in progression of various diseases.

A mitochondrion consists of four major compartments: the outer mitochondrial membrane (OMM), the intermembrane space (IMS), the inner mitochondrial membrane (IMM), and mitochondrial matrix (MM). The OMM contains $8-10 \%$ of the total proteins, mostly protein translocators, pore forming proteins, and fission and fusion proteins of mitochondria encoded by nucleus and synthesized at the cytosolic ribosomes. Based on the size, small low molecular weight compounds usually participate in diffusion to cross the OMM, high molecular weight large molecular entities use protein translocators and pores to cross this membrane which has much similarities with the cell membranes. IMM is densely packed with complex structure with unusually high protein to phospholipid ratio providing restrictive environment for entrance of chemical entities into the matrix. Furthermore, the 
negative mitochondrial membrane potential $\left(\Delta \psi_{\mathrm{m}}\right)$ of $\sim-160$ to $-180 \mathrm{mV}$ that prevails across the membranes imposes additional level of difficulty for foreign molecules to cross into the matrix (7). A schematic view of different compartments in the mitochondria is depicted in

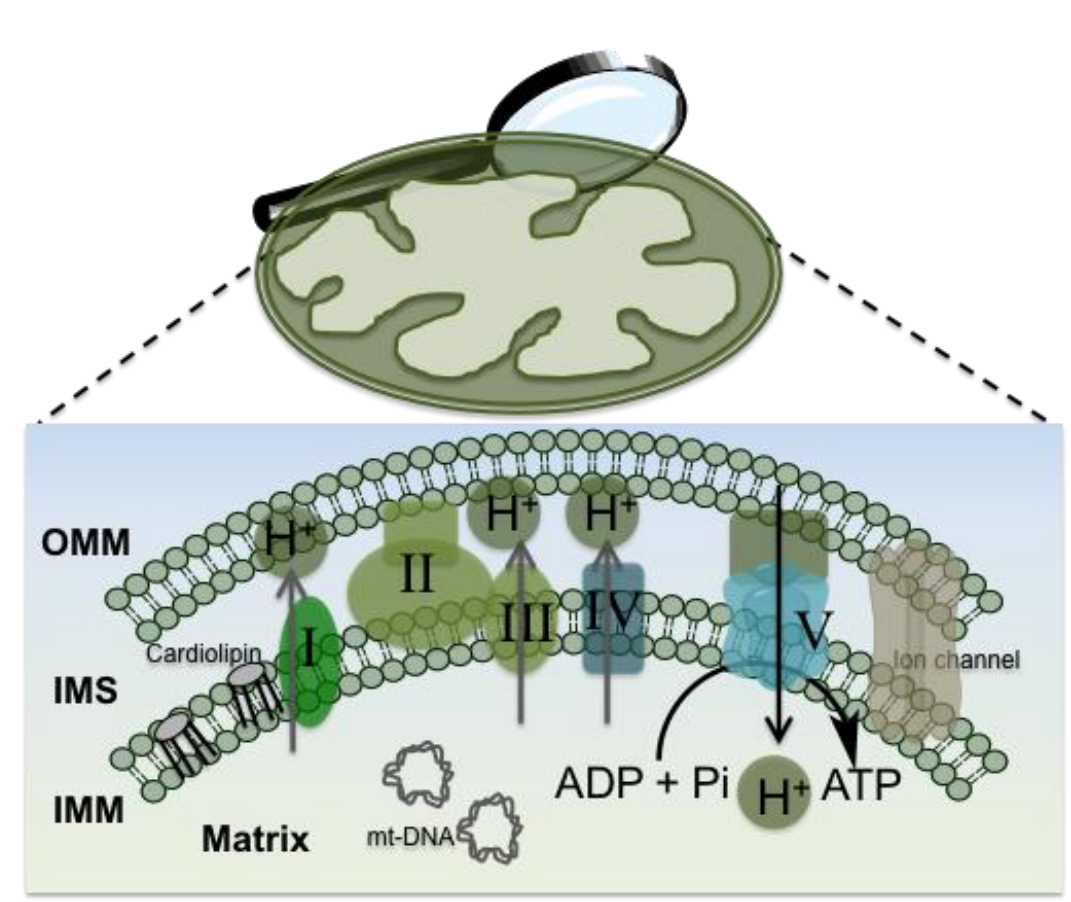

Figure 2. Schematic overview of different parts of mitochondrion.

\section{Figure 2.}

We recently published a short review on mitochondria targeted technologies for cancer therapeutics (8). In this review, we highlight mitochondrial targets and strategies to use nanotechnology tools for therapeutic interventions of cancer, as well as cardiovascular disease (CVD) and mitochondrial dysfunction related diseases.

\section{Mitochondrial Targets for Cancer}

Mitochondria of cancer cells acquire altered characteristics, such as hampered OXPHOS and enhanced rates of glycolysis, hyperpolarized mitochondria, changes in the expression of permeability transition pore complex (PTPC) components (9-12). Skulachev and coworkers showed that certain organic cations can penetrate the mitochondrial membrane and these cations can be used to deliver therapeutics inside the mitochondrial matrix upon covalent conjugation $(13,14)$. Thereafter, several mitochondria targeted therapeutics were developed where triphenylphosphonium (TPP) cation was used as a 
mitochondria-targeting ligand (15-17). These molecules have delocalized cationic charge over high hydrophobic surface area to penetrate the IMM of mitochondria. A few other low molecular weight molecules are known in the literature to target mitochondria, but upon in vivo administration small molecular entities often display poor pharmacokinetic (PK) and undesirable biodistribution (bioD). Additionally, low molecular weight small molecules often loose biological activity upon covalent modification with functionalities essential for insertion of mitochondria targeting moieties. Over the last few decades, nanotechnology made significant impact for generation of drug delivery systems to improve bioD and PK profiles of therapeutics (18-23). However, these efforts are limited to the cellular level and there is substantial lack of progress for development of nanodelivery platforms for subcellular targeting, such as, mitochondria-targeted drug delivery systems. A summary of therapeutic delivery vehicles known to date for mitochondrial association of therapeutics and the specific targets in the mitochondria is represented in Table 1. A number of non-polymeric delivery systems targeted to the mitochondria are graphically shown in Figure 3.

\begin{tabular}{|c|c|c|}
\hline Therapeutics & $\begin{array}{l}\text { Targeting groups (in bold face) } \\
\text { on nanodelivery vehicles }\end{array}$ & Target and its location \\
\hline 3-Bromopyruvate & Au-TPP NPs (24) & HK-II in OMM \\
\hline CIPhIQ Acid & PAMAM-CIPhIQ Acid (25) & TSPO and OMM \\
\hline Lonidamine (LND) & $\begin{array}{l}\text { DSPE-PEG-DQA (26) } \\
\text { PLGA- } b-P E G-T P P(27)\end{array}$ & $\begin{array}{l}\text { PTP, HK-II inhibitor, OMM, } \\
\text { IMM and MM }\end{array}$ \\
\hline PTX & 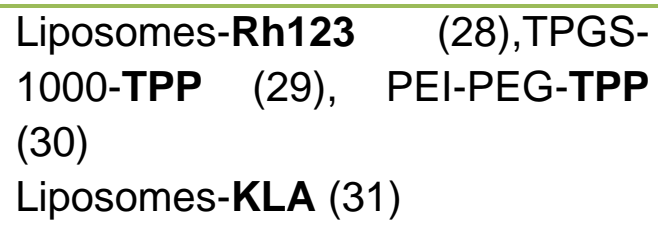 & Unknown in $\mathrm{MM}$ * \\
\hline Curcumin & $\begin{array}{l}\text { PLGA- } b \text {-PEG-TPP } \\
\text { DQAsomes-DQA (32) }\end{array}$ & Antioxidant in MM and IMS \\
\hline
\end{tabular}




\begin{tabular}{|c|c|c|}
\hline DNase I, PI, RNA & (DF-)MITO-Porter (33-35) & MM \\
\hline 2, 4-DNP & PLGA- $b$-PEG-TPP (27) & $\begin{array}{l}\text { Protonphore in IMM and } \\
\text { matrix }\end{array}$ \\
\hline$\alpha$-TOS & PLGA- $b$-PEG-TPP (27) & $\begin{array}{l}\mathrm{BCl}-2 \text { protein inhibitor and } \\
\text { antioxidant in OMM, IMM } \\
\text { and } \mathrm{MM}\end{array}$ \\
\hline $\begin{array}{l}\text { DNA and other } \\
\text { therapeutic genes }\end{array}$ & $\begin{array}{l}\text { PAMAM-G-5-TPP }(30,36) \text { and } \\
\text { DQAsomes-DQA }(37,38)\end{array}$ & mtDNA in MM \\
\hline DOX & $\begin{array}{l}\text { PEI-TPP (39), Liposomes-STPP } \\
(40)\end{array}$ & Complex I of \\
\hline $\begin{array}{l}\mathrm{Pt}(\mathrm{II}) \text { and } \mathrm{Pt}(\mathrm{IV}) \\
\text { drugs and prodrugs }\end{array}$ & $\begin{array}{l}\text { MWCNTs-Rh-123 (41) } \\
\text { PLGA-PEG-TPP }(42)\end{array}$ & $m t D N A$ in $M M$ \\
\hline Ceramide & Liposomes-STPP (43) & $\begin{array}{l}\text { Apoptosis inducer, IMS, } \\
\text { IMM and MM }\end{array}$ \\
\hline Sclareol & Liposomes-STPP (44) & $\begin{array}{l}\text { Apoptosis inducer, IMS, } \\
\text { IMM and MM }\end{array}$ \\
\hline Resveratrol & DSPE-PEG-DQA (36) & Antioxidant in MMand IMS \\
\hline $\begin{array}{l}\text { Daunorubicin and } \\
\text { amlodipine }\end{array}$ & Liposomes-DQA $(45,46)$ & $\begin{array}{l}\text { Apoptosis inducer, IMS, } \\
\text { IMM and MM }\end{array}$ \\
\hline CCl-779 & $\begin{array}{l}\text { Liposomes-Zwitterionic } \\
\text { oligopeptide ( } 47)\end{array}$ & mTOR in IMS and matrix \\
\hline $\mathrm{CoQ}_{10}$ & PCL-TPP (48) & ETC in MM \\
\hline $\begin{array}{l}\text { Topotecan } \\
\text { hydrochloride }\end{array}$ & TPGS1000-DQA (49) & $\begin{array}{l}\text { Topoisomerase I inhibitor } \\
\text { and MM }\end{array}$ \\
\hline $\begin{array}{l}\text { TPP=Triphenylphosph } \\
\text { membrane, CIPhIQ } \\
\text { Polyamidoamine, TSI } \\
\text { distearoylphosphatidy } \\
\text { glycolic acid)-polyeth } \\
\text { pore, IMM=Inner } r \\
\text { Tocopheryl polyethyle } \\
\text { Poly(ethylene imine)- } \\
2,4-\mathrm{DNP}=2,4-\text { din } \\
\text { succinate, BCl2= B } \\
\text { triphenylphosphonium } \\
\text { Rhodamine 123, E } \\
\text { rapamycin, CoQ } 10= \\
\text { inhibitor-779 }\end{array}$ & $\begin{array}{l}\text { onium, HK-II=Hexokinase-II, } \\
\text { cid =1-(2-chlorophenyl)isoquinoline- } \\
\mathrm{O}=\text { Translocator protein, DSPE-PEC } \\
\text { ethanolamine-dequalinium, PLGA } \\
\text { lene glycol-triphenylphosphonium, } \\
\text { itochondrial membrane, PTX=Pa } \\
\text { e glycol } 1000 \text { succinate- triphenylph } \\
\text { olyethylene glycol-triphenylphospho } \\
\text { trophenol, IMS = Intermembrane sf } \\
\text { cell lymphoma } 2 \text {, DOX = Dox } \\
\text { MWCNTs = Multi-walled carl } \\
\text { C=electron transport chain, mTC } \\
\text { Coenzyme } Q_{10}, P C L=\text { polycaprolac }\end{array}$ & $\begin{array}{l}\text { OMM=outer mitochondria } \\
\text {-3-carboxylic acid, PAMAM= } \\
\text { G-DQA=Polyethylene glycol- } \\
\text { A- } b \text {-PEG-TPP=Poly (lactic-co- } \\
\text { PTP=Permeability transition } \\
\text { aclitaxel, TPGS-1000-TPP= } \\
\text { hosphonium, PEI-PEG-TPP = } \\
\text { nium, KLA= D[KLAKLAK]2, } \\
\text { pace, } \alpha-T O S=\alpha \text {-tocopheryl } \\
\text { xorubicin, STPP = Stearyl } \\
\text { rbon nanotubes, Rh123 = } \\
\text { OR =mammalian target of } \\
\text { ctone, CCI-779 = Cell cycle }\end{array}$ \\
\hline
\end{tabular}




\subsection{Targets for cancer in the $O M M$}

The OMM imposes only weak barrier compared to IMM in navigation of foreign molecules to the mitochondria. The OMM contains voltage-dependent anion channels (VDAC) (50). These protein-based channels non-specifically transport ions, nucleotides, and other molecules to the IMS. The VDAC is known to mediate apoptosis by releasing cytochrome c (cyt $c$ ) and also provides a platform for interaction of pro- and anti-apoptotic members of B-cell lymphoma $2(\mathrm{BCl} 2)$ family as well as hexokinase I (HK-I) and HK-II that are overexpressed in various cancer types (51-56). These proteins participate in rapid growth of cancer cells and provide apoptosis suppressive properties. VDAC also contributes to enhanced cholesterol contents in cancer cells compared to normal cells. Thus, targeting VDAC in OMM can be important for treatment of cancer.

In cancer cells, both HK-I and HK-II are tightly bound to the VDAC at the OMM (57, 58). This HK-VDAC interaction deviates pyruvate towards lactate production and results in preventing cellular apoptosis. Thus, interfering HK binding to VDAC either by HK inhibitors or by using molecules that compete with VDAC for HK binding can result in novel therapeutics for cancer. Lonidamine (LND), 2-deoxyglucose, and 3-bromopyruvate (3-BP) are commonly used drugs for inhibition of $\operatorname{HK}(57,59)$. Efficacious delivery of these molecules can boost the therapeutic potency by several folds using NP based scaffolds. Mitochondria-targeted gold nanoparticles (AuNPs) functionalized with 3-BP and lipophilic TPP cations with delocalized positive charge to specifically target the $\Delta \psi \mathrm{m}$, were recently developed for delivery of 3-BP to the mitochondria (24). These targeted NPs carrying 3-BP demonstrated enhanced ability to modulate cancer cell metabolism by inhibiting glycolysis as well as demolishing OXPHOS process as compared to 3-BP formulated in a nontargeted NP or free 3-BP. Further, the anticancer activity of targeted AuNPs containing 3-BP 
was improved upon laser irradiation by exciting the surface plasmon resonance band of AuNPs and thereby utilizing a combinatory effect of chemo and photothermal therapies.

(a)

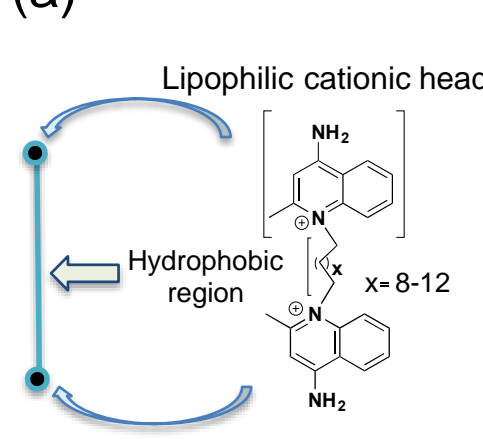

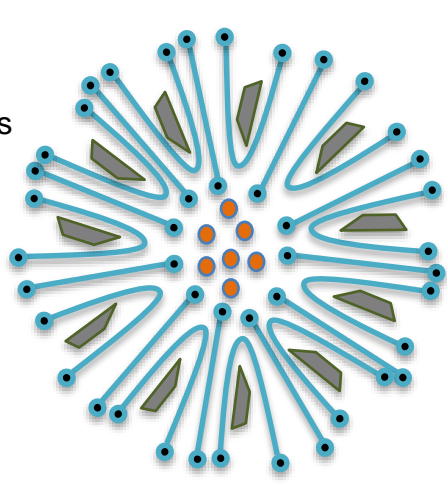

Hydrophobic drug

Hydrophilic drug (b)

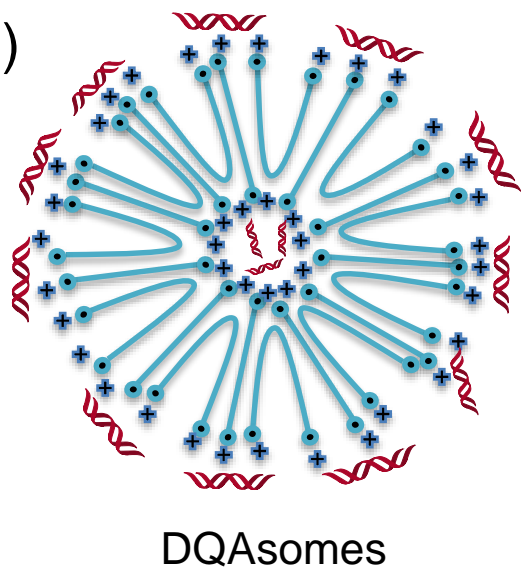

(c)

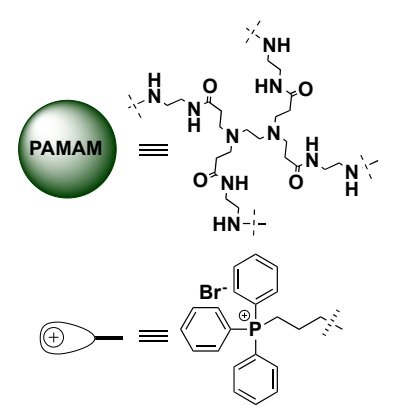

(d)

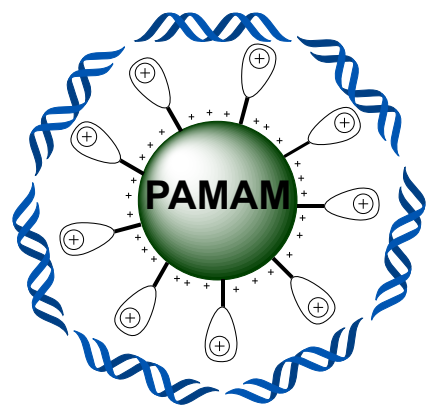

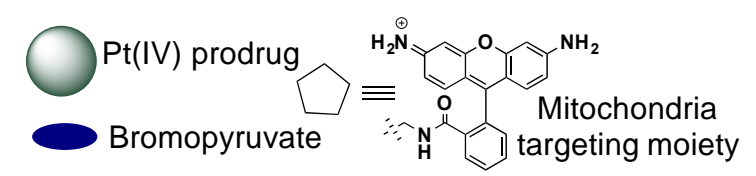

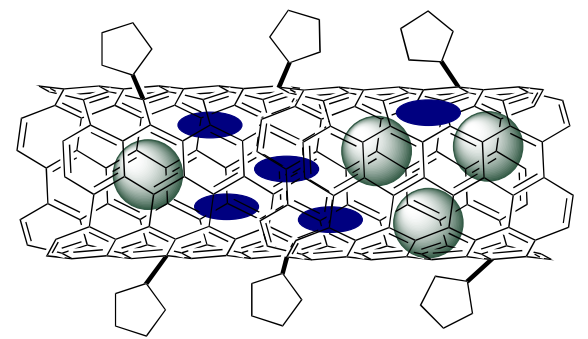

Figure 3. Schematic diagrams for the different mitochondria targeted scaffolds derived by amphiphilic DQA cations, PAMAM and carbon nanotubes. (a) Structure of amphiphilic dequalinium (DQA) cation and its drug entrapped micellar nanostructures; (b) DQA based nanomicelles for gene delivery to mitochondria; (c) TPP anchored PAMAM based dendrimers for gene delivery to mitochondria; (d) Rh110 functionalized carbon nanotubes based mitochondria delivery of dual drugs.

The translocator protein (TSPO) is a transmembrane protein primarily associated to the OMM (60). Higher expression of TSPO was found in aggressive and metastatic prostate and breast cancers $(61,62)$, and thus this protein can be considered as a target for cancer therapy. A G(4)-polyamidoamine (PAMAM) scaffold using 1-(2-chlorophenyl)isoquinoline-3carboxylic acid (CIPhIQ acid) as a TSPO inhibitor and lissamine (Liss) as an imaging agent was constructed (25). This construct was evaluated for its theranostic property in C6 rat 
glioma and MDA-MB-231 human breast cancer cells. The bright and localized cellular fluorescence was observed with CIPhIQ-PAMAM-Liss construct and it exclusively colocalized with the Mitotracker green supporting association with the mitochondria. Thus, these PAMAM based synthetic dendrimers that internalized into the cell and target the mitochondria can be used for delivery of mitochondria-acting therapeutics.

A liposome-based carrier system, MITO-Porter, was developed to deliver macromolecules such as green fluorescence protein (GFP) (63). This liposome based system delivered GFP to the mitochondria using a fusion pathway.

The $\mathrm{BCl}-2$ family is comprised of both pro- and anti- apoptotic proteins located in the OMM that regulate apoptosis by ascertaining mitochondrial outer membrane permeabilization (MOMP). Many tumors express anti-apoptotic $\mathrm{BCl}-2$ protein to circumvent apoptosis. Selective delivery of inhibitors and peptides that bind to the active site of $\mathrm{BCl}-2$ would lead to a better therapeutic option to evade tumor growth $(64,65)$. The $\mathrm{BCl}-2$ homology $3(\mathrm{BH} 3)$ protein preferentially binds to $\mathrm{BCl}-2$ through its homology domain and neutralizes its activity to induce apoptosis $(66,67)$. Small molecules mimicking the topology of $\mathrm{BH} 3$, referred as $\mathrm{BH} 3$ mimics, can bind and deactivate the function of pro-apoptotic $\mathrm{BCl}-2$ and serve as promising drug candidates (68-70). $\mathrm{BH} 3$ mimetic small molecules, ABT-737, ABT-263, gossypol, AT-101, and alpha-tocopheryl succinate ( $\alpha$-TOS) along with other chemotherapeutics, show promising selectivity in targeting pro-apoptotic proteins and increased efficacy $(71,72)$. However, clinical outcomes show that these drugs have severe dose dependent adverse effects such as thrombocytopenia (73). Nanotechnology-based targeted delivery might find applications to reduce the toxicity and increase therapeutic efficacy of these molecules. 


\subsection{Targets for Cancer in the IMM and MM}

The IMM is composed of convoluted invaginations termed as 'cristae' with high surface area. The presence of unusual phospholipid, CL and high protein to lipid ratio in the IMM allow topological alterations for reorganization of the membrane to deliver multiple functions under tightly regulated signaling cascade. IMM comprises of critical membrane proteins and enzymes, including those from electron transport chain (ETC), ions, and metabolite transporters such as the adenine nucleotide translocase (ANT), the mitochondrial calcium uniporter (MCU), and ATP synthase essential for the survival of cell. MM composed of a variety of soluble proteins, enzymes of Kreb's and fatty acid cycles, biomolecules, ions, ribosomes, and mtDNA. ETC in the IMM generates a proton gradient across the IMM to drive ATP production by ATP synthase. Cancer cells are characterized with their different phenotypes in terms of the expression of various biomolecules and proteins. Modulating their phenotypic characteristics by means of inhibiting and/or activating certain pathways can lead to effective therapeutic regimens for cancer treatment.

The PTPC forms as a super channel that comprises VDAC/ANT complex. This super channel allows transport of variety of small molecules including ATP and adenosine diphosphate (ADP). Compounds that modulate the VDAC/ANT complex channel can serve as potent candidate. One such candidate is LND that has ability to initiate apoptosis in cancer cells. In the recent past, delivery of therapeutic genes for the expression of various pro-apoptotic proteins, mtDNA damaging agents, antioxidants, small molecules, and antiapoptotic protein inhibitors was achieved for the effective mitochondrial targeted treatment strategies in cancer.

Despite the vast understanding of mtDNA-derived defects, both at the genetic and biochemical proportions, there is no effective treatment modality in hand due to the lack of 
approaches that can provide effective mitochondrial gene delivery. Torchilin and coworkers designed a mitochondria-specific transfection vector based on delocalized lipophilic cation $1,1^{\prime}$-decamethylene bis(4-aminoquinaldiniumchloride) or dequalinium (DQA) that shows mitochondria association properties (74). Its amphiphilic nature promotes liposome-like structures popularly known as DQAsomes with positively charged surface. DQAsomes expeditiously bind and shield DNA and their liposomal structures can encapsulate small molecules. Binding of DNA to these liposomes was confirmed by competitive binding of SYBR $^{\mathrm{TM}}$ dye. Complete loss of DNA-dye complex fluorescence was observed upon increasing the molar equivalents of DQAsomes in a DNA-dye mixture precludes the SYBR ${ }^{\mathrm{TM}}$ dye from binding to the DNA (74). These liposomes deliver DNA in the form of 'DQAplexes' and are able to transfect cells in vitro with efficiency comparable to lipofectamine (37). Upon interaction of these 'DQAplexes' with intact mitochondria results in the release of DNA cargo from the DQAsomes (38). The utility of DQAsomes for entrapment of small molecules was extended as one of the first mitochondria drug delivery vehicles to deliver drugs in their pristine form $(75,76)$. Paclitaxel loaded DQAsomes were demonstrated to retard the growth of human colon cancer in nude mice $(75,77,78)$. Lu and coworkers have synthesized DQA appended polyethylene glycoldistearoylphosphatidylethanolamine (DQA-PEG2000-DSPE) conjugate to prepare liposomes for delivery of resveratrol in the mitochondria (36). The DQA appended liposomes significantly increased the uptake and mitochondrial association properties. These liposomes induced apoptosis both in non-resistant and resistant cancer cells and demonstrated subsequent release of cyt $c$. Significant antitumor activity of these liposomes were demonstrated both in tumor spheroids model as well as in xenograft model of cisplatin resistant A549/CDDP cells in nude mice. Augmented anticancer efficacy was shown when 
mitochondria targeting resveratrol liposomes were co-administered with chemotherapeutic 'vinorelbine' loaded liposomes (36). This approach was further extended to efficacious codelivery of LND and epirubicin using similar mitochondrial targeted DQA appended liposomes (26). Chemotherapeutic agent daunorubicin and an inducer of apoptosis amlodipine were incorporated in the DQA functionalized liposomes for their delivery in the mitochondria. These liposomes selectively induced mitochondria mediated apoptosis and exhibited significant tumor growth reduction in vivo $(45,46)$. DQA was also used with TPGS1000, known as vitamin E polyethylene glycol succinate, to construct mitochondria targeting liposomes for the delivery of chemotherapeutic drug, topotecan hydrochloride a topoisomerase I inhibitor. These mitochondria targeted topotecan entrapped liposomes

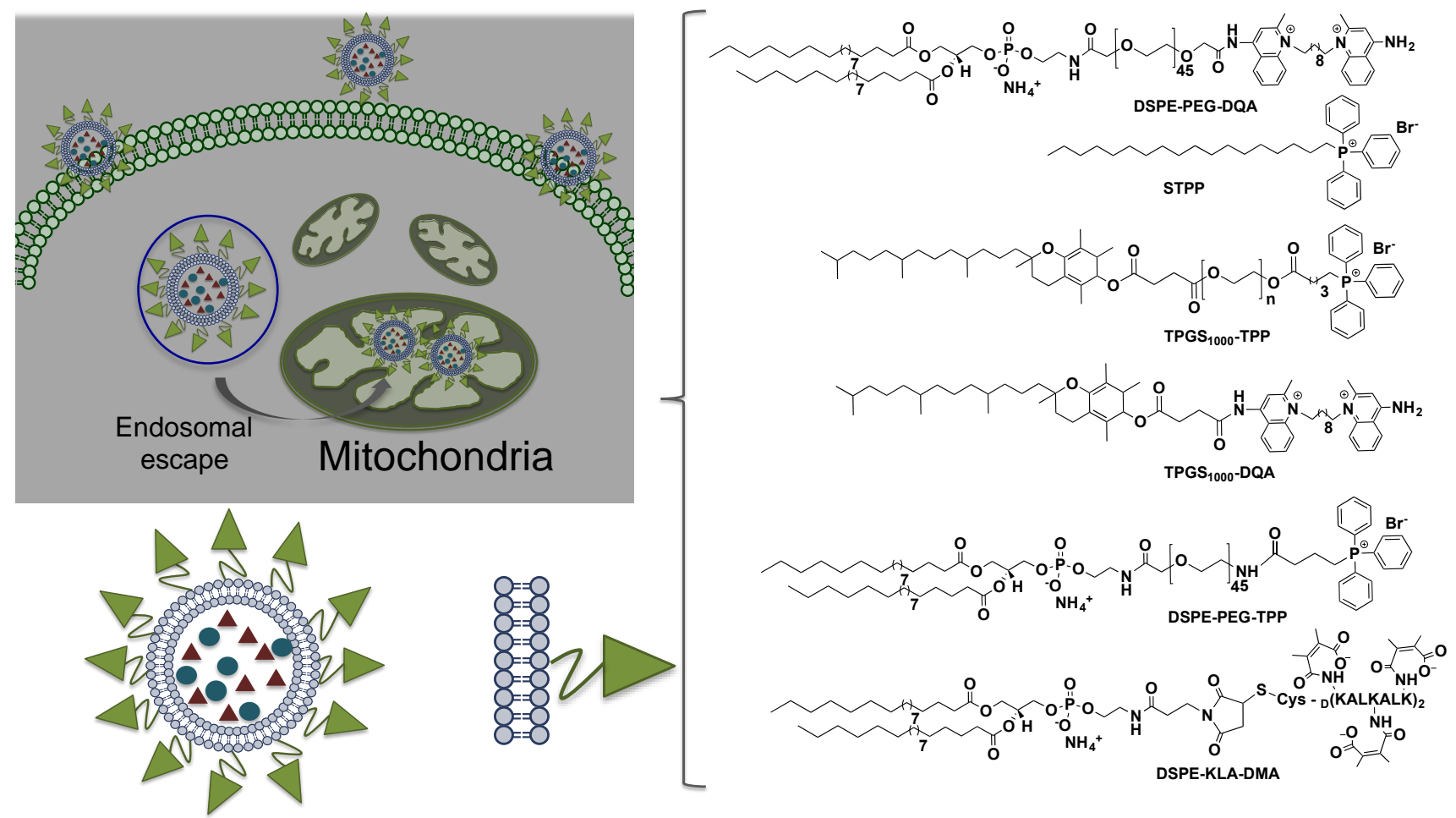

Figure 4. Schematic diagrams for the TPP functionalized liposomes constructed based on different phospholipids bearing mitochondria targeted agents. Structure of mitochondria targeted liposome and demonstration of its endosomal escape capability to finally reach mitochondria matrix, and chemical structures of mitochondria targeted molecules and lipids used for the preparation of liposomes to target mitochondria. 
demonstrated higher efficacy for treatment of chemo-resistant cancer and showed inhibition of metastases in vivo (49).

Another class of hyper-branched synthetic molecules, dendrimers, which can be modified to install multiple drugs and targeting moieties, were demonstrated to be effective as nanocarrier systems for delivery of various pharmaceutical agents to the mitochondria Torchilin and coworkers described development of a mitochondria-targeted G(5)-D-Ac-TPP scaffold where mitochondria targeting was achieved using covalent conjugation of TPP with the surface functionalities of the dendrimer and remaining free $\mathrm{NH}_{2}$ were acetylated for nonspecific binding. Cellular and subcellular compartmentalization studies with FITC coupled G(5)-D-FITC-Ac-TPP showed effective mitochondrial localization and this formulation was found to be non-toxic to cells (30). Thus, G(5)-D-Ac-TPP scaffold can be used as a nontoxic mitochondria-targeted nanocarrier for delivery of therapeutics either by loading in the dendrimer core through electrostatic interaction or by covalent conjugation on the surface. Subsequently, Cheng and coworkers utilized the G5-TPP dendrimer scaffold to deliver nucleic acids to mammalian cell mitochondria (79). These TPP conjugated PAMAM polymeric gene vectors demonstrated targeting aspects towards mitochondria resulting in better transfection efficacy in HeLa and COS-7 cells. Transfection efficiency of these scaffolds was shown to be greater than the commercially available transfection reagent SuperFect and comparable with Lipofectamine 2000. The increase in the transfection ability of G5-TPP dendrimers to the mitochondria was correlated to DNA binding/unpacking ability, efficient endosomal escape, and better serum resistance (79). Further investigation and systematic studies are needed to explore the utility of these scaffolds for co-delivery of therapeutic genes along with anticancer drugs. 
Similar approach was extended by Tsiourvas and coworkers to deliver doxorubicin (DOX) using lipophilic decyl-TPP functionalized poly(ethylene imine) hyperbranched polymer (PEI-TPP) to the cancer cell mitochondria (39). The resulting nanoassembly, PEIDOX-TPP, with $\sim 100 \mathrm{~nm}$ mean diameter was shown to be effective at sub-micromolar concentration to deliver DOX to the mitochondria.

Suitably functionalized liposomes with cellular and subcellular-targeting moieties can provide an alternative therapeutic avenue for site directed drug delivery. A number of liposome-based mitochondria targeted delivery vehicles are summarized in Figure 4. Weissig and coworkers demonstrated the utility of liposomes in mitochondria targeting via appropriate surface modification with mitochondriotropic residues (80). Mitochondriotropic liposomes were prepared with stearyl TPP (STPP) bromide as the targeting ligand. Intracellular localization of these liposomes was demonstrated by using $0.5 \mathrm{~mol} \%$ phospholipid conjugated rhodamine-PE dye along with other phospholipids and STPP as the targeting ligand. These liposomes were found to demonstrate mitochondrial association properties in BT-20 human breast cancer cells. Weissig and coworkers also used STPP liposomes to deliver ceramides to the mitochondria to induce apoptosis with improved metabolic toxicity as compared to the non-targeted delivery systems (43). These mitochondria-targeted ceramide delivery systems were further evaluated to exhibit antitumor activity in vivo. Biodistribution of STPP liposome was found to be similar to that of nontargeted analogues. In another example, water insoluble anticancer drug, sclareol, was delivered using STPP based mitochondria targeted liposomes to improved therapeutic index (44). A dual targeting approach was adopted by Murthy and coworkers to deliver DOX in cancerous cells followed by association with the mitochondria using STPP and folic acid (FA) functionalized liposomes (40). These DOX containing FA-STPP based liposomes 
exhibited greater cytotoxicity compared to non-targeted and simple targeted liposomal formulations depicting synergistic effects of FA and STPP.

D- $\alpha$-tocopheryl polyethylene glycol 1000 succinate-TPP (TPGS1000-TPP) cation was used as a mitochondria targeting ligand that was incorporated in the liposomal membrane to deliver paclitaxel (PTX) (29). This selective mitochondrial delivery of PTX induced apoptosis in resistant cancer cells (29). Similar strategy was employed to incorporate rhodamine-123 (Rh123) as a mitochondria targeted ligand on the liposomes for efficacious delivery of PTX. These Rh123 functionalized liposomes were shown to have higher cellular uptake with increased accumulation in the mitochondria as evaluated by fluorescence microscopy and FACS analysis. These Rh123 functionalized liposomes showed an increase in the potency of PTX as compared to its free drug (28). In another report, polyethylene glycolphosphatidylethanolamine (PEG-PE) based liposomes were used to deliver PTX (81). These TPP appended liposomes were shown to have less toxicity compared to the earlier reported STPP based liposomes. Significant increase in the cytotoxicity and anti-tumor efficacy of PTX-loaded TPP-PEG-liposomes were observed compared to unmodified PTXloaded liposomes both in vitro and in vivo. However, systematic in vitro and further in vivo studies are needed to prove the exact behavior and potential of these liposomes as therapeutics. A multistage $\mathrm{pH}$ responsive break down property based zwitterionic oligopeptide appended liposome was prepared to remove surface barriers for exposing the cationic species on the surface to direct therapeutics to the mitochondria (47). $\mathrm{HHG}_{2} \mathrm{C}_{18}$ consists of two amino acid groups from glutamic acid and histidine, hydrophilic block of $\mathrm{pH}$ cleavable group hexahydrobenzoic amide, and hydrophobic block of two stearyl chains, to mimic natural phospholipids. The surface charge of $\mathrm{HHG}_{2} \mathrm{C}_{18^{-}} \mathrm{L}$ is negative under physiological conditions ( $\mathrm{pH} 7.4)$, whereas, at the tumor site surface charge gets reverses to 
positive in presence of slightly acidic milieu to increase tumor cellular uptake. Owing to the presence of imidazole of histidine, these nano-constructs facilitate proton sponge effects to escape endosome and lysosomes for subsequent localization in the mitochondria. A specific inhibitor $\mathrm{CCl}-779$, of mammalian target of rapamycin (mTOR), a serine/ threonine protein kinase that mediates cell growth and cell proliferation was incorporated in these nano constructs to block mitochondrial mTOR. Significant potency enhancement of mitochondria targeted $\mathrm{CCl}-779 / \mathrm{HHG}_{2} \mathrm{C}_{18} \mathrm{-}$ - constructs was observed both in vitro and in vivo. However, the complex nature of these nano-constructs with less versatility, limits their use as potent drug delivery agents.

Recently a liposomal construct possessing extracellular $\mathrm{pH}$ responsive and mitochondrial targeting properties was used for efficacious delivery of PTX (31). The peptide $\mathrm{D}[\mathrm{KLAKLAK}] 2$ (KLA) amines were shielded by 2, 3-dimethylmaleic anhydride (DMA) and further combined with DSPE to yield DSPE-KLA-DMA (DKD). The DKD bearing liposomes were able to reverse their surface charge in the acidic tumor extracellular $\mathrm{pH}(\sim 6.8)$ from negative to positive to preferentially accumulate in the mitochondria. These liposomes demonstrated enhanced efficacy in treating A549 cells and A549/Taxol resistant cells in vitro as well as in vivo.

Polymeric NPs derived from biocompatible and biodegradable components are explicatively used as alternative delivery agents to the liposomes $(23,82)$. Owing to their amenable variations in hydrophobic and hydrophilic blocks composition, these polymers can be used to encapsulate both hydrophilic and hydrophobic therapeutics via emulsion or nanoprecipitation methods, respectively (83). A sustained and controlled drug release profile with overall higher stability and non-immunogenic properties of polymeric NPs as compared to the conventional liposomes have the ability to increase the potency of the 
delivered therapeutics $(84,85)$. A class of biodegradable polyesters, such as, poly (glyocolic acid) (PGA), poly(lactic acid) (PLA), and their copolymer poly(lactic-co-glycolic acid) (PLGA), and polycaprolactone (PCL) are used frequently to build hydrophobic corona of NPs whereas the FDA approved PEG is used to make hydrophilic shell on the NP core (86). The hydrophobic corona provides stability, PEG allows for longer retention time and immune system escape within the body. Further, the PEG blocks can be attached with the targeting moieties to enhance uptake. These desirable qualities along with the broad scope for chemical modification of polymers make polymeric NPs versatile delivery systems for mitochondrial delivery.

A recent example demonstrated use of mitochondria-targeted polymer based nanodelivery system to deliver coenzyme $Q_{10}\left(C_{0} Q_{10}\right)$ to combat oxidative stress (48). These NPs were constructed from a miktoarm polymer of formula $A B C$ where $A=P E G ; B=T P P$, and $C=P C L$ (Figure 5). The resultant micelles had high drug loading with small critical micellar concentration. Inefficient localization of the NPs inside the mitochondria were observed in confocal microscopy studies due to the disadvantage lies in its structural design with TPP moieties near the hydrophobic PCL (48).
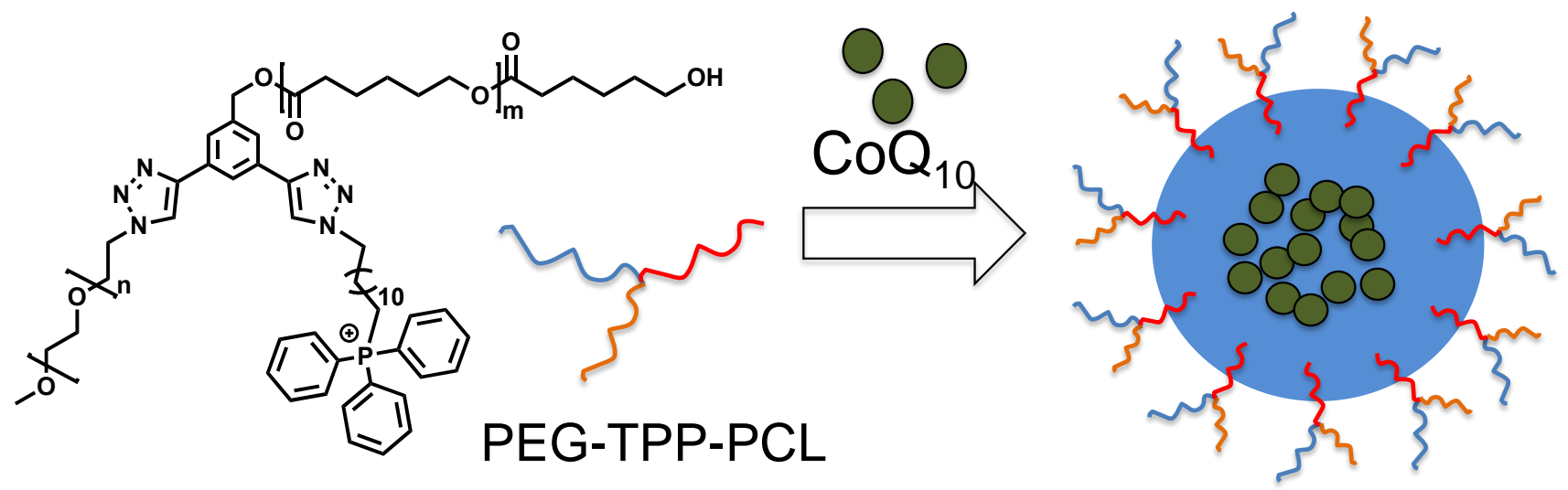

Figure 5. Triblock star polymer containing PEG, $P C L$, TPP and $\mathrm{CoQ}_{10}$ loaded mitochondria targeted NPs. 
Our group has developed a TPP terminated PLGA- $b$-PEG based block copolymer to target mitochondria (Figure 6). Upon self-assembly, amphiphilic block copolymer composed of PLGA forms a core and PEG as a corona with mitochondria targeting TPP on the surface $(21,27,42,87)$. The TPP moieties on the surface of the NPs provide cumulative positive charge delocalized over a large hydrophobic phenyl rings making these NPs ideal system for penetration in the lipid membranes. Further these NPs take the advantage of $\Delta \psi_{m}$ that exists across the IMM to get associated with the mitochondria. These PLGA-based NPs were fine-tuned for their size and surface charge to provide better mitochondrial association using an engineered polymer blending technology (27). We found that an optimum size of $<100 \mathrm{~nm}$ and a positive zeta potential of $>22 \mathrm{mV}$ is needed for efficient mitochondrial affinity. Owing to the unique biological properties, such as, non-toxicity and nonimmunogenicity along with the facile cellular and subcellular uptake, and controlled release of the payload allow the use of these scaffolds as novel drug delivery vehicles (Figure 6). The presence of unique topology with lipophilic cations on the NP surface allow for endosomal escape. Cellular and subcellular distribution was assessed through the quantitative measurement of the $\mathrm{Cd}$ from the CdSe quantum dot (QD) loaded targeted and non-targeted NPs. Fluorescence microscopy imaging of targeted and non- targeted NP treated cells indicated significantly higher association of targeted NPs with the mitochondria of cells whereas the non-targeted NPs were mainly found scattered in the cytosol. The versatility of these NPs was further demonstrated through delivering a variety of mitochondria-acting therapeutics, such as, curcumin, mitochondrial decoupler 2,4dinitrophenol (2,4-DNP) as an anti-obesity drug, LND, and $\alpha$-TOS. A significant increase in the potency was observed by directing these therapeutics to the mitochondria. 


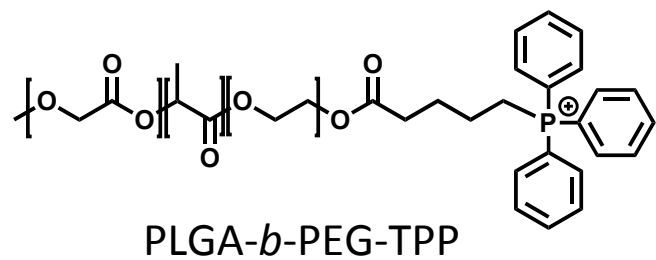

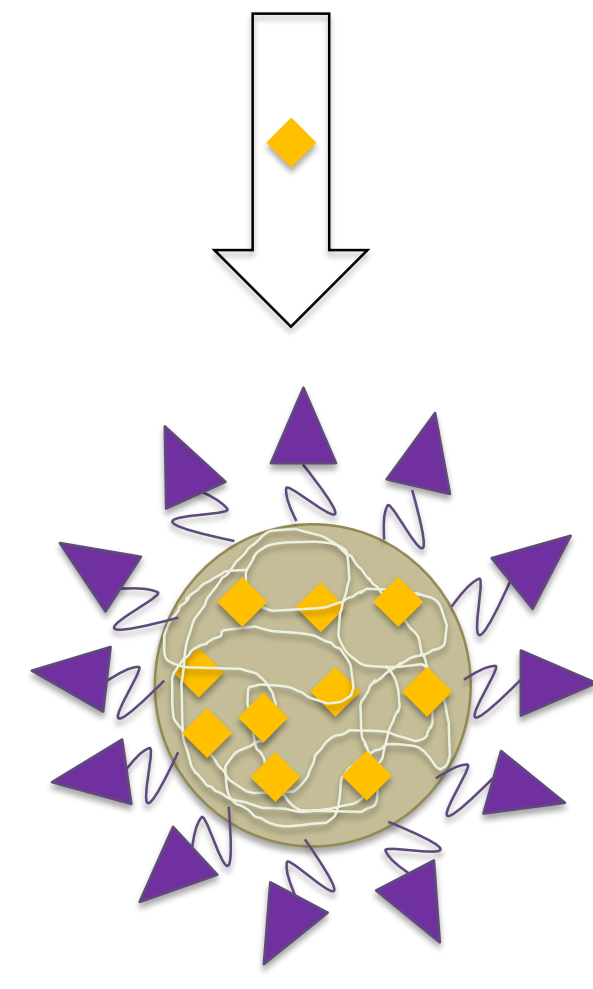

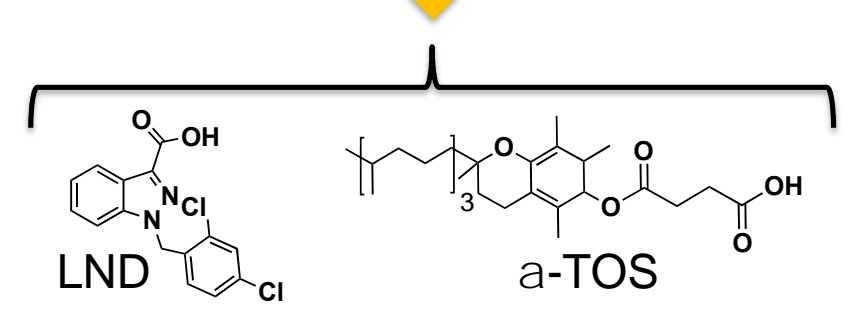

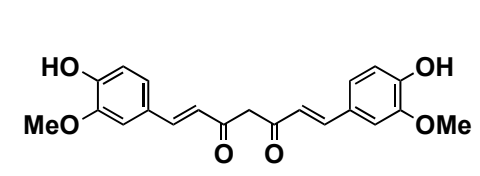

Curcumin

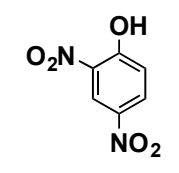

2,4-DNP

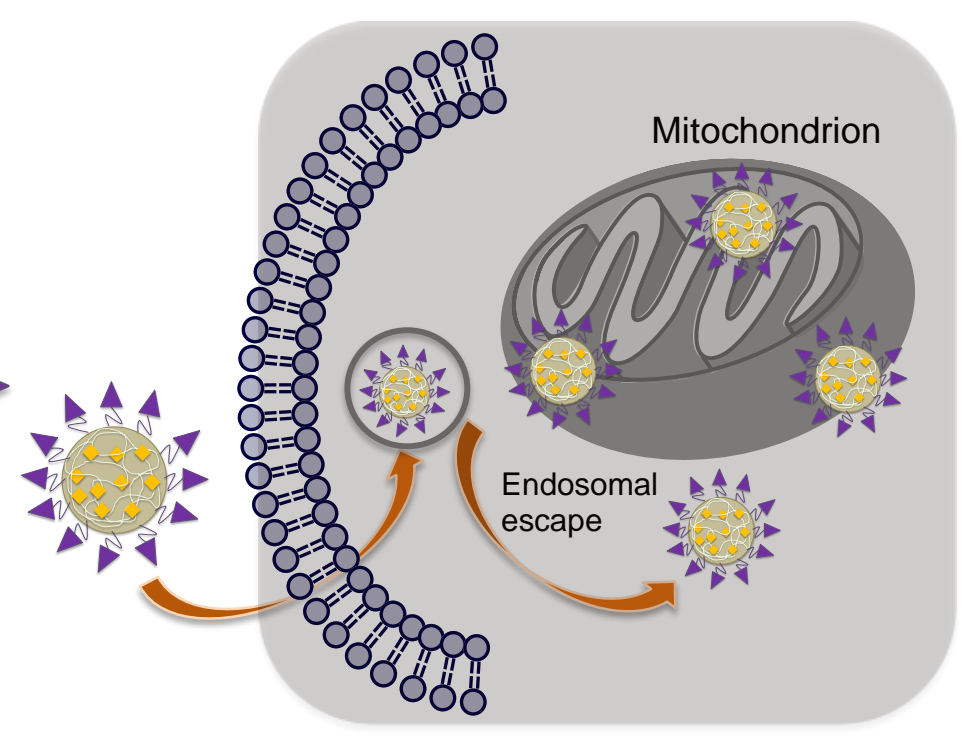

Figure 6. Schematic presentation of engineered drug loaded polymeric NP decorated with TPP cations on the surface to target mitochondria.

After successful demonstration of mitochondria directed delivery of the above mentioned therapeutics, recently we used these biocompatible polymeric NPs to deliver a cisplatin prodrug to the mitochondria to access mtDNA which lack NER machinery (42). Directing DNA damaging agents such as cisplatin to the mitochondria can potentially address the problems associated with conventional platinum-based compounds $(88,89)$. For this purpose, a hydrophobic mitochondria-targeted cisplatin prodrug, Platin-M, was synthesized using a strain promoted azide-alkyne cycloaddition reaction (90). Platin-M was loaded in PLGA- $b$-PEG-NPs for controlled release of cisplatin in the MM. Cisplatin released from Platin-M in the mitochondria can attack mtDNA to form Pt-DNA adducts and induce cell 
death. Significantly higher activity of Platin-M and its targeted-NPs in cisplatin-resistant cells was observed. Thus, a precise strategy for mitochondria targeting of cisplatin for chemoresistance cancers using a unique dual-targeting approach is an alternative route for cisplatin-based therapy (42). Recently, this technology was studied in a large animal model by demonstrating the safety and toxicity of mitochondria-targeted NPs loaded with Platin-M (91). This study also highlights the ability to manufacture the mitochondria targeted NPs in large scale.

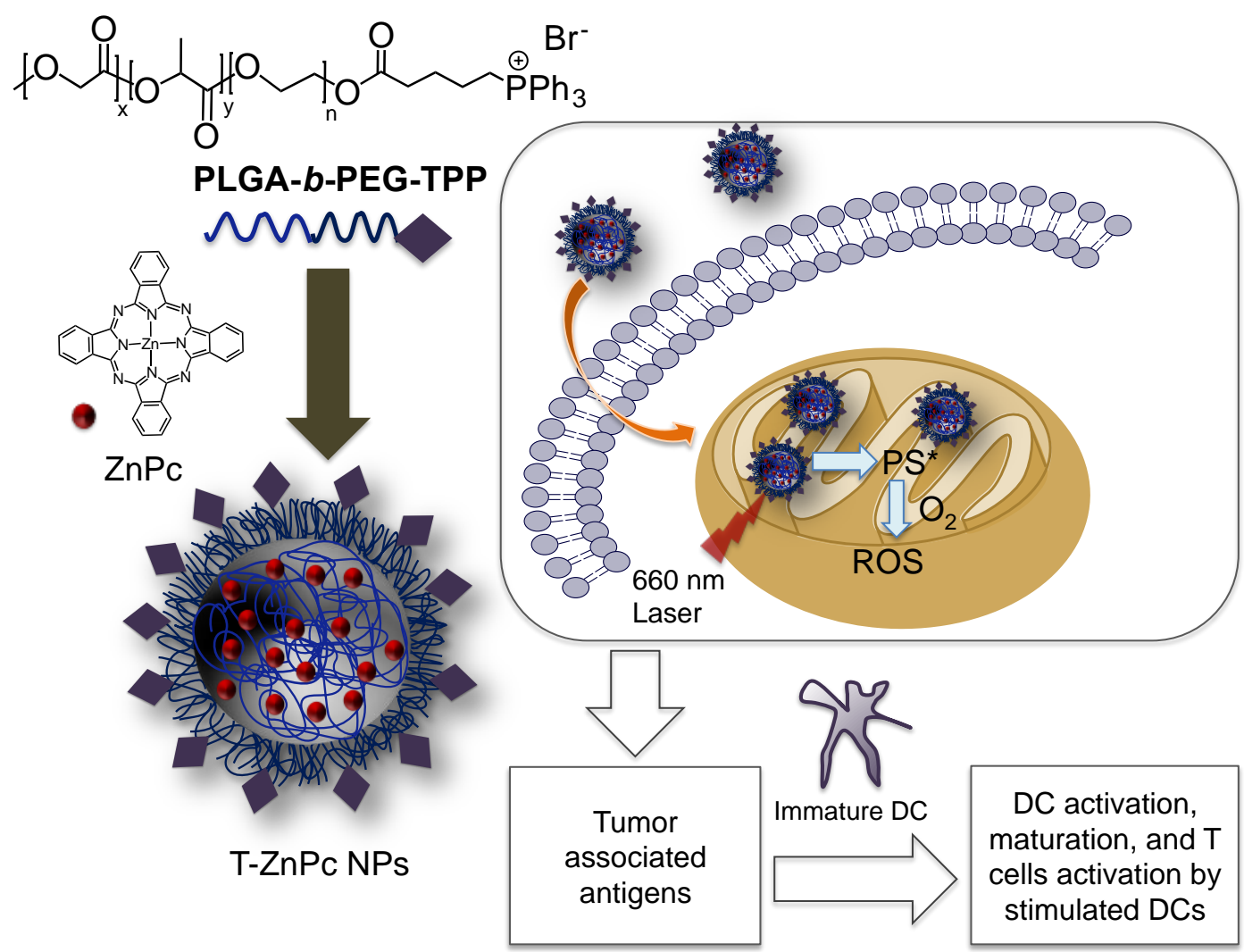

Figure 7. Schematic diagram for the construction of mitochondria targeted $\mathrm{ZnPc}$-loaded NPs for PDT using a $660 \mathrm{~nm}$ laser light to produce ROS to causes cell death and subsequent activation of DCs using TAAs.

These biocompatible polymeric NPs were also used in mitochondria targeted photodynamic therapy (PDT). PDT has emerged as an anticancer tool that involves the use of a photosensitizer (PS) that is excited with the aid of light for production of singlet oxygen 
that damages cellular components and promote apoptosis. Zinc phthalocyanine (ZnPc) was entrapped inside the NPS of PLGA-b-PEG-TPP polymer to act on mitochondria upon irradiation $(87,92,93)$. Efficacious delivery of $\mathrm{ZnPc}$ to the mitochondria produced singlet oxygen upon radiation locally inside the mitochondria to induce apoptosis and increased the potency. Tumor associated antigens (TAAs) generated from the treatment of breast cancer MCF-7 cells with targeted NPs loaded with ZnPc upon light irradiation activated dendritic cells (DCs) to generate high levels of interferon-gamma, a crucial cytokine considered as a product of T and natural killer cells (Figure 7). This noteworthy ex vivo DC stimulation ability

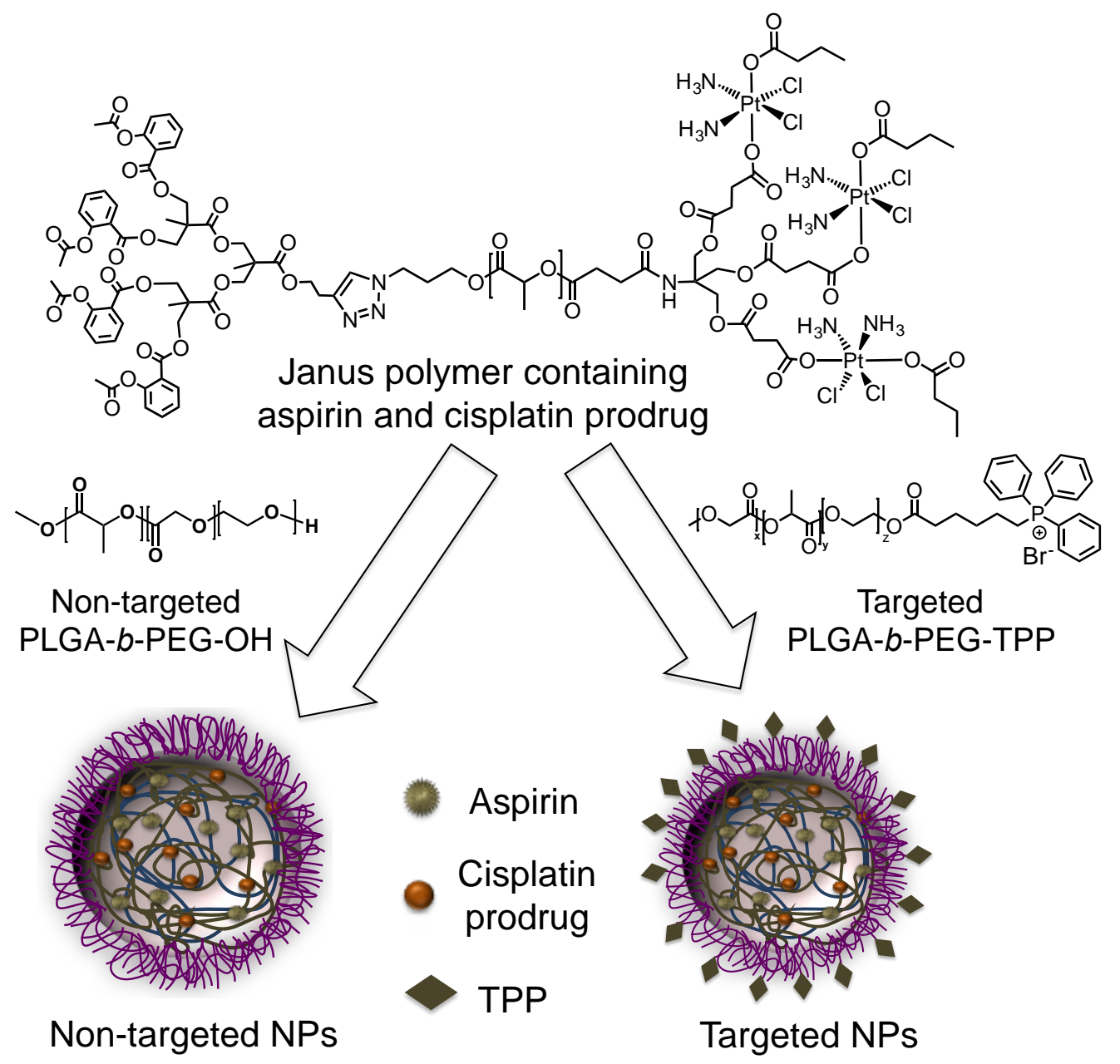

Figure 8. Delivery of a combination of aspirin and a cisplatin prodrug using blended NPs constructed from a Janus polymer containing both the therapeutics and mitochondria targeted PLGA-b-PEG-TPP. 
of the TAAs generated from mitochondria-targeted PDT opens up the possibility of using mitochondria targeted light activated PS as possible vaccine for cancer.

Very recently, this mitochondria targeted polymer was used to deliver a combination of cisplatin and aspirin in the mitochondria of prostate cancer cells (94) (Figure 8). We developed a Janus polymer containing a precisely controlled ratio of cisplatin prodrug and aspirin. The NPs obtained by blending this polymer with PLGA-b-PEG-OH demonstrated low cellular uptake profile. However, the blended NPs resulting from mitochondria-targeted PLGA-b-PEG-TPP and Janus polymer showed enhanced cellular uptake. We also demonstrated the use of this polymer in delivering anti-inflammatory agents such as aspirin for diseases where inflammation mediated processes are involved. Our recent work showed the use of this polymer to reduce inflammation in vivo using an aspirin analogue as an antiinflammatory drug (95).

\section{Mitochondrial Targets for Cardiovascular Diseases (CVD)}

Heart diseases which include atherosclerosis, coronary heart disease (CHD), stroke, myocardial ischemia and reperfusion (IR) injury, myocardialinfarction, cardiomyopathy $(\mathrm{CM})$, and chronic heart failure (HF), are the leading cause of mortality and morbidity worldwide (96). Most of these diseases are associated with cardiac cell death by apoptosis or necrosis, where mitochondria play an essential role (97-99). Necrosis is mainly triggered by opening of the mitochondrial permeability transition pore (mPTP) which results in swelling of the mitochondria and OMM rupture (100). ROS such as superoxide anions and hydroxyl radicals cause oxidation of proteins, membrane phospholipids and mtDNA, release of cyt $c$ and apoptotic inducing factor (AIF), ultimately leading to apoptosis (101).

Atherosclerosis mainly contributes to CVD-related mortality and acute coronary syndrome (102-106). Many studies suggested that mitochondrial $\mathrm{K}^{+}$channels have an 
important role in cardioprotection. The mechanism of cardioprotection, though unclear, may involve mild uncoupling of the mitochondrial membrane potential causing $\mathrm{Ca}^{2+}$ overload and ROS generation. Mild swelling resulting from influx of $\mathrm{K}^{+}$into the mitochondria may also regulate the PT pore (107). Mitochondrial potassium sensitive ATP channel (mKATP) also plays critical role in cardioprotection. Complex II is related to mKATP in such a way that complex II inhibitors open mKATP, and mKATP openers inhibit complex II (108). A possible mechanism of cardioprotection could be the washout of the inhibitor that inhibits ROS generation and $\mathrm{Ca}^{2+}$ overload allowing a gradual reintroduction of the electron flux.

Cardiomyopathy is characterized by decreased cardiac function $(107,109-111)$. CM is the precursor to heart failure and acute $\mathrm{CM}$ is mainly caused due to myocardial ischemia. Cardiac remodeling and hypertrophy are often caused by permanent occlusion. The reperfusion phase of IR injury particularly injures mitochondria the most. Mitochondrial derangements that occur during the post-IR phase in the heart includes symptoms such as: (i) inhibition of respiratory complexes

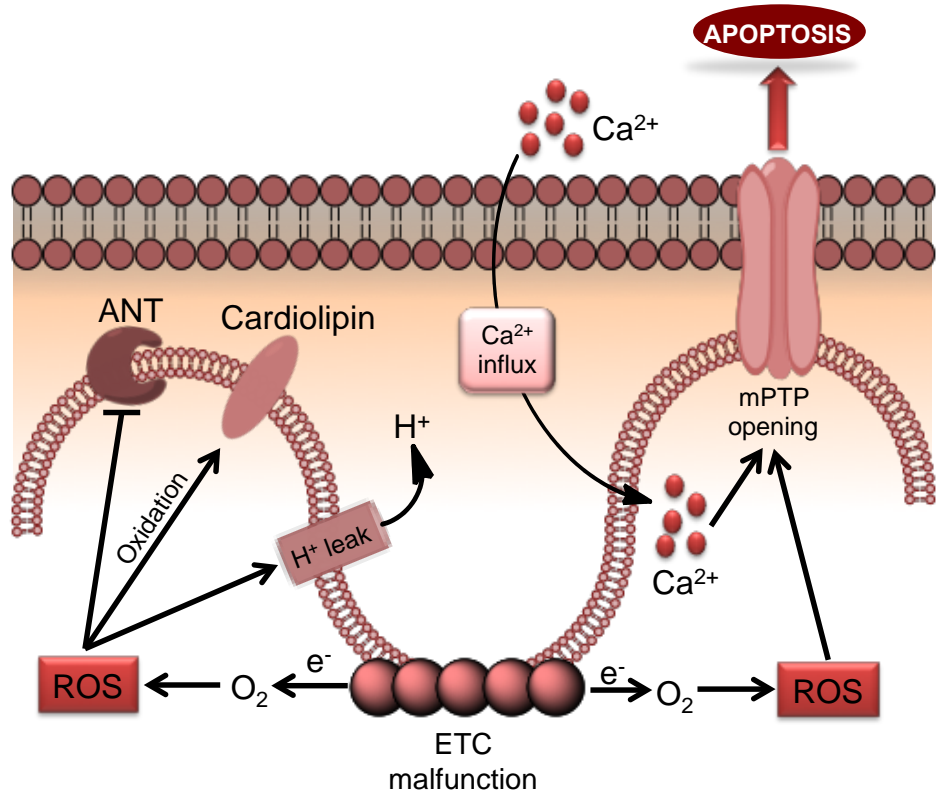

Figure 9. Changes in mitochondrial functional pathways associated with cardiomyopathy.

(112) and ANT (113), (ii) higher proton leak of the inner membrane (114), (iii) oxidation of $\mathrm{CL}$ and other associated membrane protein dysfunctions (115), (iv) excessive ROS generation (116), (v) opening of mPTP and consequent release of proteins such as cyt c (117), (vi) nucleotide depletion (118), and (vii) mitochondrial $\mathrm{Ca}^{2+}$ overload (Figure 9). 
Inefficient metabolic processes such as these lower the ATP and phosphocreatine levels and decreases the metabolic reserve and flexibility.

Here, we highlight the potential targets in the mitochondria for therapeutic interventions of CVDs (Figure 10).

\subsection{Targets for CVD in the OMM}

OMM separates the IMS from the cytosol. It is relatively permeable to solutes with

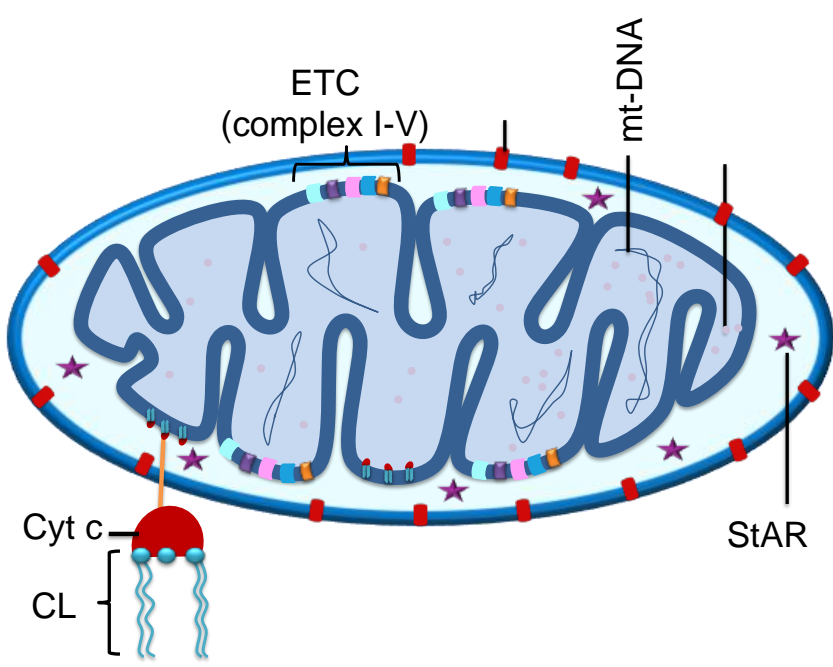

Figure 10. Possible targets located in the mitochondrion for CVDs. ETC-electron transport chain, VDAC-voltage dependent anion channel, mtDNA-mitochondrial DNA, StAR-steroidogenic acute regulatory protein, CL-cardiolipin, cyt $c$-cytochrome $\mathrm{C}$.

mass up to $500 \mathrm{Da}$ due to the VDAC protein porin (119). OMM regulates the metabolites, ions, and information exchange between mitochondria and cytosol, in which VDAC plays a critical role. Kay et. al. reported that the functional state of $\mathrm{OMM}$ is a sensitive indicator for ischemic damage of mitochondria (120). VDAC controls uptake of $\mathrm{Ca}^{2+}$ from cytosol to the mitochondria and the release of ROS from the mitochondria to the cytosol (121). The $\mathrm{Ca}^{2+}$ homeostasis is indispensable for cardiac function. The loss of $\mathrm{Ca}^{2+}$ homeostasis causes contractile dysfunction and arrhythmias in failing myocardium, leading to HF (122-124). ROS (e.g. superoxide) are closely related to pathological conditions, such as inflammation, IR injury, and drug metabolism (125-127). VDAC is a rational target in attenuating HR and IR by inhibiting cardiomyocyte apoptosis. Salnikov. et al. reported activity of gold nanoparticles (AuNPs) upon the OMM of ventricular cells and isolated cardiac mitochondria of rats (128). 
They demonstrated that $3 \mathrm{~nm}$ but not $6 \mathrm{~nm}$ particles could penetrate the OMM and accumulate in IMS via VDAC. The inhibitors of VDAC such as König polyanion and 4,4'diisothiocyanatostilbene-2,2'-disulfonic acid can prevent this permeabilization activity. VDAC closes during the apoptosis cascade and inhibits the release of ATP or uptake of ADP and respiratory substrates from the cytosol to mitochondrion (119). The VDAC inhibitors, such as $\mathrm{BH} 4$ derivative peptides $(129,130)$, ruthenium red (RuR) (131), ruthenium amine binuclear complex $\left(\mathrm{Ru}_{360}\right)$ (132), fluoxetine (133), and modulators of $\mathrm{Ca}^{2+}$ regulation can be potential therapeutic agents for heart-related disease caused by accelerated cardiac cell apoptosis.

\subsection{Targets for CVD in the IMS}

Redox control in the IMS contributes to various pathways in the mitochondria, including apoptotic signaling, assembly of respiratory chain components, antioxidant activation (134). Loss of redox control by ROS may lead to initial apoptotic cascades and dysfunction of respiratory and energetic systems. Cardiomyopathy and HF may be caused by the ROS in this compartment in cardiac cells. Mitochondrial cholesterol transporter, steroidogenic acute regulatory protein (StAR) binds to cholesterol mainly at the OMM and shuttling cholesterol from OMM to IMM for steroid biosynthesis $(135,136)$. This transportation process is the rate limiting step for steroidogenesis and its disruption may lead to atherosclerosis $(137,138)$. Therefore, the ROS in IMS and StAR may be used as targets for cardiomyopathy and atherosclerosis. Several NP-based delivery systems show promising approaches to cardiomyopathy, ischemic stroke, and HF (139-141). Cerium and yttrium oxide NPs are known to show direct antioxidants properties to protect cells from a variety of oxidative stress (142). For example, Niu et. al. reported efficiency of $\mathrm{CeO}_{2} \mathrm{NPs}$ in inhibition of progressive cardiac dysfunction and remodeling using an ischemic 
cardiomyopathy murine model, in which $\mathrm{CeO}_{2}$ NPs acted as effective free radical scavengers to block oxidative stress (143). In their studies, $\mathrm{CeO}_{2} \mathrm{NPs}$ were intravenously injected via tail vein into 5-week old monocyte chemoattractant protein (MCP)-1 mice. The $\mathrm{CeO}_{2} \mathrm{NP}$ treatment showed inhibition of progressive left ventricular dilatation and dysfunction. Quantitative analysis of anti-3-nitrotyrosine antibody indicated that $\mathrm{CeO}_{2}$ treatment interrupted peroxynitrite, a marker of oxidative stress, formation in the myocardium of MCP-1 mice. The $\mathrm{CeO}_{2} \mathrm{NPs}$ also demonstrated attenuated levels of $\mathrm{NO}_{x}$ in terms of total nitrated protein in the serum, indicating reduced myocardial oxidative stress. They proposed that $\mathrm{CeO}_{2}$ NPs inhibited the expression of endoplasmic reticulum stressassociated genes at mRNA and protein levels, attenuating apoptosis in the myocardium.

\subsection{Targets for CVD in the IMM}

Mitochondrial electron transport is a major subcellular source of ROS in the failing myocardium because of the extreme abundance of mitochondria in cardiac myocytes (101). The regulation of $C L$ plays significant roles in optimal activity of mitochondrial enzymes, cholesterol translocation by activating the mitochondrial cholesterol side chain cleavage, energy metabolism, and apoptosis (144). The alteration of CL is associated with CVD. It was reported that the loss of CL in the heart is correlated to the development of HF (145). Oxidation of $\mathrm{CL}$ results in decrease of OXPHOS and HF on reperfusion, which could be hampered or attenuated by melatonin (146). The preservation of CL contents demonstrated to have less alteration of mitochondrial complex I and III, reduced oxidative damage, and enhanced function of heart. CL is susceptable to peroxidative attack due to the presence of unsaturated double bonds and the proximity to ETC proteins. The ROS induced peroxidation of CL results in dissociation of cyt $c$ from IMM, causing apoptosis (147) which is associated with heart ischemia (148). The oxidized $C L$ (oxCL) produces natural occurring 
antibodies, which allows to act in the first line defense to invade pathogens during CVD (149). Thus, CL can be a possible target for the application of nanotechnology tools to combat CVD.

The ATP generation is essential for maintaining cardiac function. Mitochondrial respiratory and ATP synthase activity are implemented in the decrease of cardiomyocytes in human and dog with chronic HF $(122,150)$. HF can be regulated by $F_{1} F_{0}-A T P a s e$ in the IMM. The $F_{1} F_{0}$-ATPase normally promotes ATP synthesis, but it hydrolyzes ATP under ischemic conditions. Excessive ATP hydrolysis decreases the cardiac energy reserve leading to HF (151). Grover et al. reported selective $F_{1} F_{0}$-ATPase inhibitor BMS-199264 with significant cardio-protective profile by reducing ATP hydrolysis (152). Thus, the $F_{1} F_{0^{-}}$ ATPase can be a target for nanotechnology-based tools against HF and IR.

The mPTP inhibitors, such as cyclosporin-A (CsA) $(153,154)$, cyclophilin-D (155),

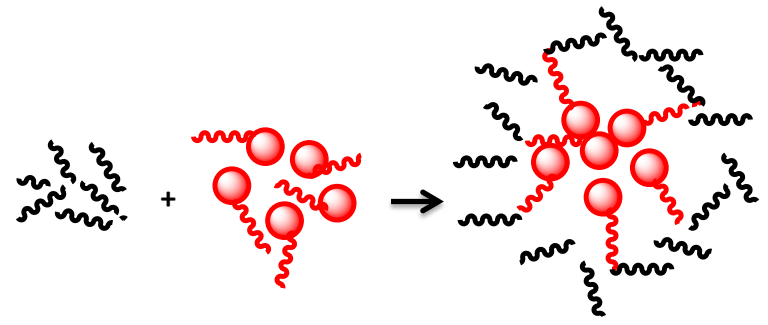

PLGA $\quad \mathrm{CoQ}_{10} \quad$ PLGA-CoQ 10 -NPs

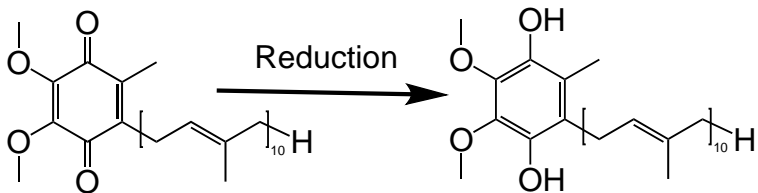

Oxidized $\mathrm{CoQ}_{10}$

(Ubiquinone)
Reduced $\mathrm{CoQ}_{10}$ (Ubiquinol)

cinnamic anilides (156), and antioxidants are known to prevent the mPTP opening. Yin et al. reported a NP system containing CsA which when used in combination with adipose-derived stem cell (ASCs) in a swine model of myocardial infarction showed therapeutic benefits (157).

$\mathrm{CoQ}_{10}$ has attracted great interest in the clinical studies for myocardial function and

Figure 11. Schematic diagram of $\mathrm{CoQ}_{10}$-NPs and its reduction process.

heart failure $(158,159)$. CoQ 10 effectively counteracts oxidative damage in IMM and improves mitochondrial efficiency, making myocardium more tolerated to 
hypoxia/reoxygenation stress $(160,161)$. PLGA-CoQ 10 NPs of $<100 \mathrm{~nm}$ were successfully prepared by an emulsion-diffusion-evaporation method, which demonstrated enhanced oral bioavailability and anti-inflammatory activity compared to free $\mathrm{CoQ}_{10}$ (Figure 11) (162). Recently, Yamada et al. reported $\mathrm{Co}_{10}$ delivery using MITO-Porter, a liposomal delivery system, to target mitochondria for preventing IR injury (163). The $\mathrm{CoQ}_{10}-\mathrm{MITO}-$ Porter was intravenously injected in the hepatic IR injury mice model. The MITO-Porter was in vivo confirmed to accumulate in the mitochondria of the liver. The fusogenic properties of MITOPorter make it possible for $\mathrm{CoQ}_{10}$ to target IMM. The delivery of $\mathrm{CoQ}_{10}$ to liver mitochondria inhibits the IR injury by preventing the ROS levels. Therefore, delivery of $\mathrm{CoQ}_{10}$ to the mitochondrial using NP-based platforms can be promising therapeutic method for CVD.

The lipophilic benzoquinone based electron carrier, idebenone (IDB), is a synthetic analogue of $\mathrm{CoQ}_{10}$. IDB acts as a free radical scavenging molecule and can thus function as an antioxidant (164). It is insoluble in water and shows limited bioavailability after oral administration. To obtain enhanced solubility and increased bioavailability of IDB, NPs were constructed using various stabilizers including hydrophilic polymers, amphiphilic polymers, and surfactants such as iabrasol, Brij 35, Pluronic F-68, Tween 80 , sodium lauryl sulphate and hydroxypropyl methylcellulose (165). Doxorubicin induced cardiotoxicity characterized by decreased body weight and heart weight was supplemented by these NPs (50 mg/kg) resulting improved body and heart weight.

\subsection{Targets for CVD in the MM}

MitoQ is one of the antioxidants that works in the MM with its ability to accumulate in the mitochondrial matrix. It was designed to mimic the endogenous antioxidant $\mathrm{CoQ}_{10}$ and has been intensively studied as a mitochondria-targeted antioxidant to decrease ROS and oxidative damage (Figure 12) (17, 166-172). Bennett and co-workers reported antioxidative 
property of MitoQ in atherosclerosis and metabolic syndrome models (173). In their studies, MitoQ was orally administered for 14 weeks in fat-fed apolipoprotein knock out $\left(\mathrm{ApoE}^{-/}\right)$and ataxia telangiectasia mutated $(\mathrm{ATM})^{+/-} / \mathrm{ApoE}^{-/-}$mice models. MitoQ treated $\mathrm{ATM}^{+/+} / \mathrm{ApoE}^{-/-}$

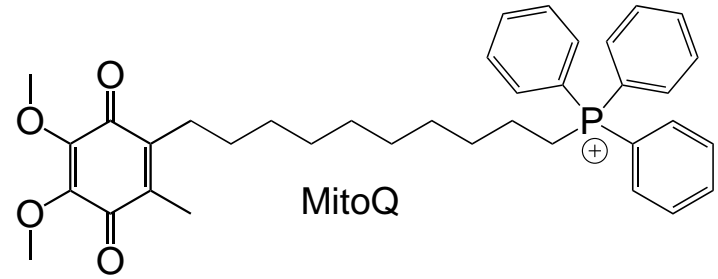

Figure 12. Structure of MitoQ. and $\mathrm{ATM}^{+/-} / \mathrm{ApoE}^{-/-}$mice showed reduced serum levels of total cholesterol, triglyceride, and low-density lipoprotein (LDL). Additionally, MitoQ treated animals demonstrated decreased plaque numbers and proliferation, and reduced mtDNA damage in the liver. The metabolic changes in mice with MitoQ may be attributed to the less oxidative damage via redox signaling pathways.

Recently, Yu et. al. reported that the mtDNA damage promotes atherosclerosis and plaque vulnerability (174). The mtDNA defects led to decreased expressions of respiratory complexes and reduced mitochondrial respiration in vascular smooth muscle cells, monocyte/macrophages, and other organs. Apoptosis and inhibition of cell proliferation along with the storage of adipose tissue promoted atherosclerosis. Furthermore, mutation of mitochondrial tRNA and/or mtDNA are associated with CHD and cardiomyopathy (175-177). Cardiac aging in mice is correlated to mtDNA mutations and deletions (178). Hence, gene therapy using NP platforms for mtDNA and/or mtRNA (179) might be effective methods to inhibit CVD.

Park et al. developed a $\mathrm{H}_{2} \mathrm{O}_{2}$-responsive anti-oxidant polymer, polyoxalate containing vanillyl alcohol (PVAX), with abilities to rapidly scavenge $\mathrm{H}_{2} \mathrm{O}_{2}$ and release vanillyl alcohol with anti-oxidant, anti-inflammatory, and antiapoptotic properties (141). They demonstrated that these nanoparticles exerted anti-oxidant and anti-inflammatory activities. Using DOXinduced cardiac and hepatotoxicity models, this work demonstrated that administration of 
PVAX NPs significantly inhibited ROS production and pro-inflammatory signals in the liver and heart of DOX-treated mice.

High density lipoprotein (HDL) based delivery vehicles are used for drugs and

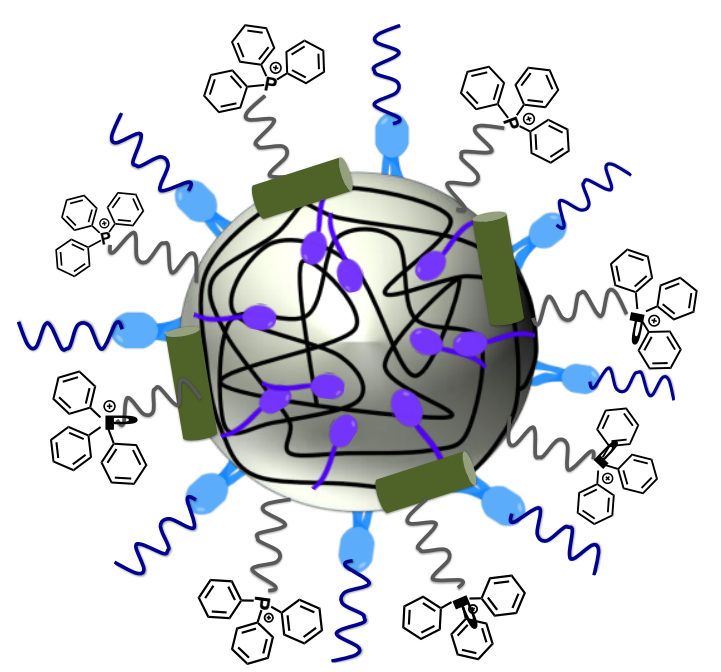

Figure 13. Schematic diagram of the mitochondriatargeted biodegradable synthetic HDL with various combonents.

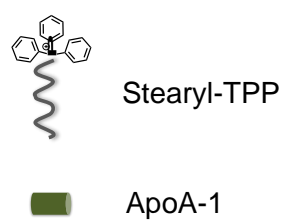

imaging agents (180). However, reconstituted HDL-based delivery systems often face the compatibility issues. Recently, our lab developed a mitochondria targeted completely synthetic HDL mimicking NP for atherosclerosis (181). This HDL mimic consists a core of biodegradable PLGA and cholesteryl oleate, a phospholipid coating layer ornamented with TPP cations for mitochondria targeting, and this lipid layer was further decorated with apolipoprotein A-I (apoA-I) mimetic L-4F peptide (Figure 13). Targeted NP-treated cells indicated the presence of the NPs mainly in the MM and the IMS; small amounts of NPs were found in the IMM or the OMM. In vivo studies in SpragueDawley rat indicated that the targeted HDL synthetic NPs were majorly distributed in the heart within $24 \mathrm{~h}$. The low dose of NPs $(10 \mathrm{mg} / \mathrm{kg})$ showed reduced lipid profile levels of cholesterol and triglyceride. This platform is promising for the plaque imaging and therapy of CVD.

\section{Targets for Mitochondrial Dysfunction Related Diseases}

Absence of effective DNA repair machinery in the mitochondria enhances the impacts of radical-induced mtDNA damage. At birth, all mtDNA copies in an individual are 
identical and this is genetically termed as homoplasmy. Ramification of mitochondria with a mixture of mutant and wild type mtDNA known by the genetic term "heteroplasmy" result in several diseases $(182,183)$. When the weightage of the mutant mtDNA exceeds a critical threshold level, cells show the abnormalities in the mitochondrial respiratory chain and this event is know as the threshold effect (184). Events associated with initial electron leak further increase the extent of electron leakage resulting in a vicious cycle. The leaked electrons and the radicals formed alter the integrity of the mitochondrial membrane. These events together cause further dysfunctions resulting in disruption of cellular energy production and aged cells. Thus, any abnormality in the mitochondria can hamper tissuespecific activities performed by this important organelle and result in mitochondrial dysfunction related disorders. A number of mitochondrial dysfunction related diseases are discussed below.

\subsection{Autism Spectrum Disorders}

Autism spectrum disorders (ASD) comprise of a set of neurodevelopmental ataxia that is recognized by behavioral changes including difficulties in communication and social intercommunication and repetitive behaviors. Nearly two decades ago, Coleman and Blass suggested that patients with ASD may exhibit abnormal carbohydrate metabolism (185). ASD was also related to the abnormality in the brain bioenergetics with impaired mitochondrial functions (186). A more recent controlled study suggested that mitochondrial dysfunctions may be present in up to $80 \%$ of children with ASD (187). Studies also suggested that mitochondrial dysfunctions and oxidative stress are closely associated. For example, a decrease in the mitochondrial function along with a simultaneous increase in biomarkers of oxidative DNA damage and decreased superoxide dismutase 2 (SOD2) activity were found in temporal lobe brain samples (BA 21) (188). In another study, markers 
associated with oxidative stress in brain tissue were observed alongside reduced ETC complex activities in the autistic children (189). A higher level of oxidative damage to mitochondrial proteins is also observed in the autistic patients. The oxidative stress markers are also related with the functioning of TCA enzyme, aconitase, and GSH/GSSG in the cerebellum and the temporal lobe (190).

\subsection{Mitochondrial Dystrophy}

Muscular dystrophies (MD) comprise of a heterogeneous group of genetic diseases identified by gradual degeneration and weakness of skeletal muscle. Among the several types of MD that exist, Duchenne muscular dystrophy (DMD) and Becker Muscular Dystrophy (BMD) are the two most commonly found ones (191). Both of these are caused by the mutations to the dystrophin gene that is located on the $p$ arm of the $X$ chromosome (192). Dystrophin protein is responsible for contraction of the myofibrils and membrane stability. $\mathrm{Ca}^{2+}$ dysregulation is implicated in MD. Since mitochondria can function as a low affinity, high capacity $\mathrm{Ca}^{2+}$ buffer system, $\mathrm{Ca}^{2+}$ dysregulation promotes $\mathrm{Ca}^{2+}$ overload of mitochondria and thus mitochondrial dysfunction. Lack of dystrophin is believed to cause membrane fragility and give rise to micro-tears in the sarcolemma. Consequently, an abnormal $\mathrm{Ca}^{2+}$ influx and mitochondrial $\mathrm{Ca}^{2+}$ overload triggers the mitochondrial permeability transition via the formation of large pore proteins spanning both inner and outer mitochondrial membranes.

Mitochondria are the main source of intracellular ROS. At low $\mathrm{Ca}^{2+}$ concentrations, the MPTP gets activated and as a result of the partial mitochondrial depolarization there is a decrease in ROS production. At high $\mathrm{Ca}^{2+}$ concentrations, there is a loss of cyt $\mathrm{c}$ and progressive gating of electron flow via the ETC and the mitochondria rapidly transitions to a non-equilibrium state and as a consequence of which the MPTP gets activated and the 
ROS levels increase (193). Studies have suggested that there is substantial decrease in the expressions of mitochondrial complexes I, III, IV and V (194). Increased levels of cyclophilin D results in an increase in sensitivity of $\mathrm{Ca}^{2+}$ induced activation of the mega channel/mPTP (195). Mdx mice, a model of DMD, when treated with the cyclophilin inhibitor Debio-025 showed reductions in mitochondrial swelling and the disease associated necrotic manifestations.

Antisense therapy involving the use of antisense oligonucleotides (AONs) is a powerful tool for introducing post-transcriptional modifications and thereby regulating disease related target genes (196). However, naked AONs suffer limited bioavailability, poor cell trafficking, and endosomal entrapment (197). Polymeric NPs composed of PEG, poly(isobutyl cyanoacrylate) (PIBCA), PLGA are used in a number of examples to deliver AONs (196). Inorganic nanomaterials such as gold, silver, silica, calcium phosphate based carriers are also used to design hybrid systems to deliver AONs (196). Recently, rapamycin

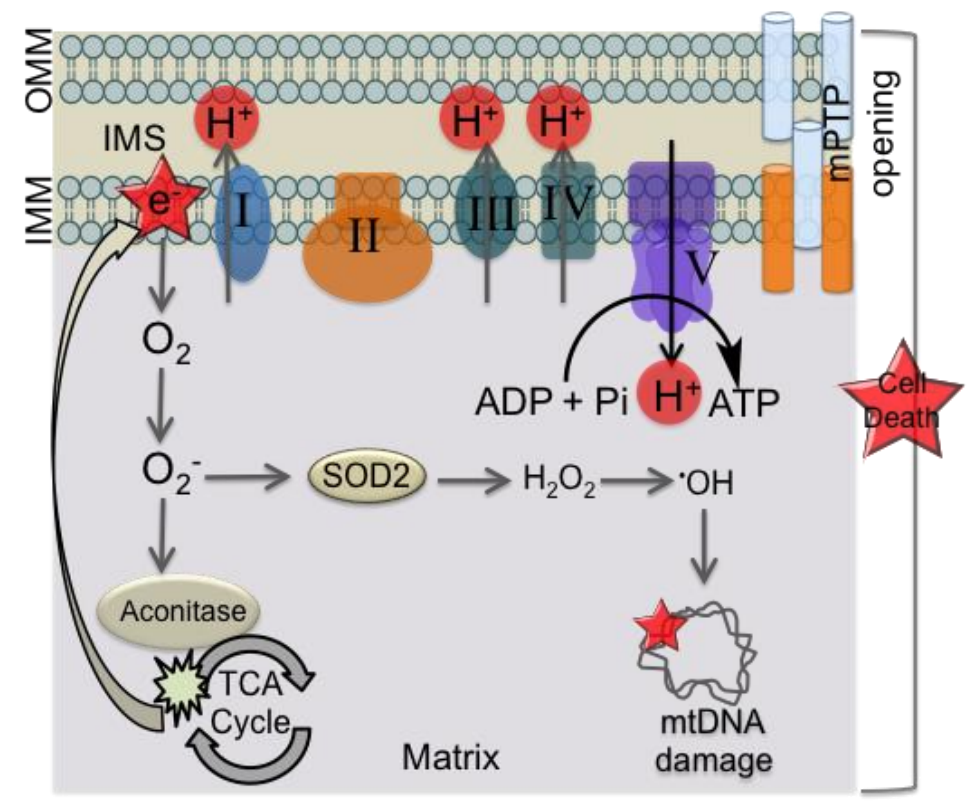

Figure 14. Changes of mitochondrial properties during the progression of epileptogenesis.
NPs have shown to target defective autophagy in MD (198). These agents do not have mitochondria specific therapeutic targets and are thus beyond the scope of this article.

\subsection{Mitochondrial Dysfunctions in}

\section{Epilepsy}

Epilepsy is typically

characterized by recurrent seizures, which consists of synchronized discharges of a large groups of 
neuronal cells that disrupt the normal functioning of the brain (199). Mitochondrial dysfunction could be one of the potential causes of epileptic seizures (199). A number of factors which get altered during epileptogenesis are shown in Figure 14. Evidences also indicate that epilepsy may be a consequence of free radicals, oxidative stress and mitochondrial dysfunction (200). Severe impairment in activity of the respiratory chain complex I was observed (201). Superoxide radicals are produced in considerable amounts during inhibition of the respiratory chain that can overload the endogenous ROS scavenging mechanisms resulting in oxidative damage to mitochondrial proteins, phospholipids and DNA. Also, recent evidences show that there is a direct relation between mitochondrial oxidative stress and DNA damage that occur during the various phases of epileptogenesis (202).

A wide range of liposomes, polymeric nanoparticles, solid nanoparticles and metallic NPs are employed to deliver a number of anti-epileptic drugs (AEDs) (203). Liposomes were used to deliver AEDs such as gamma-aminobutyric acid and phenytoin to show suppressed epileptic seizures (203). Polymeric NPs with advantages of higher stability, controlled drug release, and higher circulatory half-life were also used to deliver AEDs such as thyrotropinreleasing hormone, clonazepam (204), ethosuximide (205), valproate (206), loperamaide (207), phenytoin $(205,208)$, and carbamazepine (205).

As discussed before, ROS is well known etiological agent in epilepsy. Hidekatsu et al. successfully prolonged the anticonvulsant effect in amygdaloid-kindled rats by the use of a superoxide dismutase-liposomal formulation (209). Kizelsztein et al. observed controlled release of tempamine, a potential antioxidant, using a PEGylated liposomes in an animal model (210). $\beta$-Carotene is an antioxidant known for its epileptic convulsions. Bioavailability 
and stability of polysorbate-80-coated $\beta$-carotene nanoparticles for epileptic convulsions in mice models was found to be higher when compared to unmodified $\beta$-carotene (49).

\subsection{Amyotrophic Lateral Sclerosis}

Amyotrophic lateral sclerosis (ALS) arises from selective degeneration of the cortical motor neurons and anterior horn cells of the spinal cord. In this disease, a mutation of superoxide dismutase 1 (SOD1) causes a defect in the overall motor neuron dynamics, subsequently affecting the transport of mitochondria within neuronal cells (211). Evidence suggests that increased levels of SOD1 expression directly influence up-regulation of more than 50 mitochondrial proteins, including mitofusin 2 (Mfn2). This indicates that, in addition to destruction of ROS, SOD1also acts as a feedback regulator of membrane potential within mitochondria (211). The changes associated with mitochondria in ALS are presented in

Figure 15. Mutation in the SOD1 protein leads to misfolding, which directs its translocation

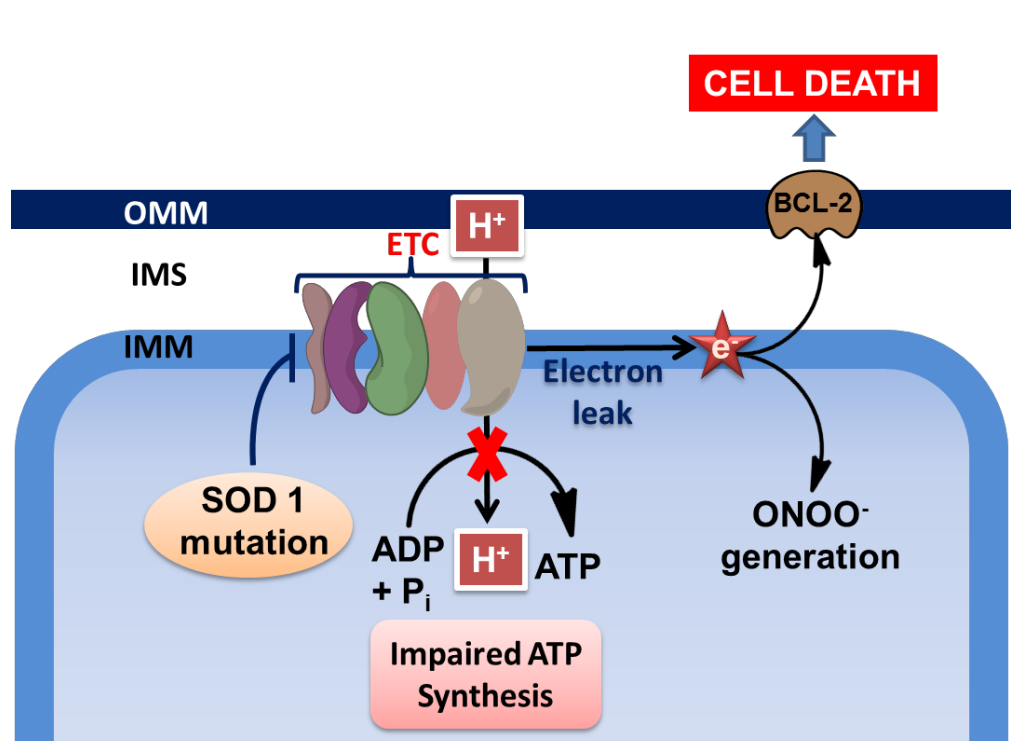

Figure 15. Mitochondrial changes during ALS.

into the mitochondrial intermembrane space causing aggregation. The mutant SOD1 protein is also the causative agent for cell death in ALS models of disease (212).

Therapeutic approaches for

ALS therapy include, vaccines targeting the epitopes of misfolded protein, adaptive immune neuroprotection, stem cell therapy as well as recent emerging applications of nanotechnology in neuroscience (213). The nascent approach of nanotechnology in this 
field have focused in part on regulating ROS production, since several results suggest that the loss of major neuronal portion in ALS is mainly due to the damages caused by ROS production. Recently PLGA-NPs carrying SOD1 to neurons was reported to provide protection against hydrogen peroxide-induced oxidative stress in human neurons (214). SOD-like mimicking activity was observed with carboxyfullerenes which demonstrated increased reactivity to superoxide radicals and a high cell permeability, and exhibited neuroprotective ability in vitro (215). In another study, a reactive product of lipid peroxidation, known as acrolein, was identified in the motor neurons of patients with ALS as well as in the brains of patients with Alzheimer's diseases. In the same study, mesoporous silica NPs loaded with hydralazine and functionalized with PEG were able to rescue acrolein-mediated apoptosis in vitro (216). AuNPs modified with SOD1 monomer and utilizing colorimetric detection system was developed for diagnosis of ALS (217). Thus, nanomedicine offers the potential to improve effective diagnosis and treatment of ALS.

\section{Mitochondrial Targets for Neurological Diseases}

Mitochondrial dysfunctions leads to severe neurological disorders (218). A number of diseases where mitochondrial dysfunctions play significant roles along with the cell type that suffer from these dysfunctions are depicted in Figure 16. Neurons are highly dependent on OXPHOS as they do not have the ability to multiply and regenerate. Thus, any dysfunction and communication gap can cause severe defects in neuronal functions (219). Oxidative stress localized in the mitochondria, disrupts calcium homeostasis as well as apoptosis, contributing to neurological diseases. These diseases include Alzheimer's disease (AD), Parkinson's, and Huntington's diseases, stroke, ALS, and psychiatric disorders (220). Defects in mitochondrial gene are also the major cause of syndromes which include: chronic progressive external ophthalmoplegia; Kearns-Sayre syndrome of chronic progressive 
external ophthalmoplegia, retinitis pigmentosa, sensory-neural deafness and cardiac conduction disturbances, Leber's hereditary optic neuropathy, syndrome of mitochondrial encephalomyopathy, lactic acidosis and stroke-like episodes, myoclonic epilepsy with ragged red fibers, and neuropathy with ataxia and retinitis pigmentosa (221).

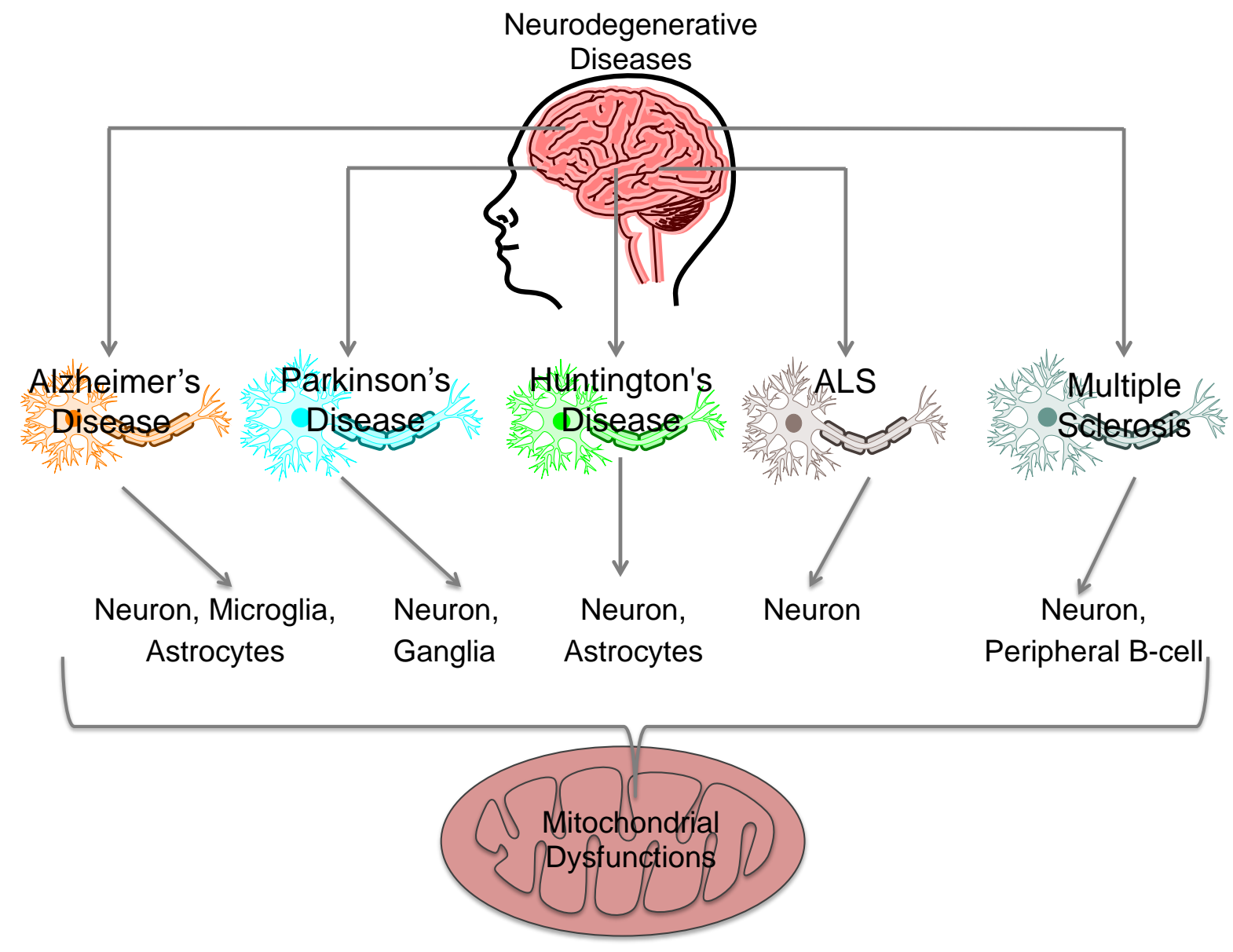

Figure 16. Mitochondrial dysfunctions in different neurodegenerative diseases along with the cell types that suffer from mitochondrial dysfunctions.

Current research assessments of mitochondrial biogenesis, mitophagy, and dynamics suggest that mitochondrion as an organelle, exhibits movement as part of neuroprotective strategies, both in case of neural disease and injuries (222). The application of nanotechnology in design and development of therapeutic materials for the treatment neurodegenerative diseases in particular where mitochondria is the target is at the 
preliminary stages of development. Despite this, recently several impressive body of research and technologies were developed, however this particular area is beyond the scope of the current review.

\section{Mitochondrial Nanomedicine: The Future}

As the mitochondria play central roles in life and death processes of cells, their abnormalities are responsible for various diseases. Nanotechnology-based toolbox can provide unique approach to target the mitochondria of diseased cells to provide "precision medicine" for better management of these diseases. The recent developing NP-based strategies have shown great promise for targeting specific sites of organ, tissue, or cells; thus, the ability to use nanotechnology may provide unexplored therapeutic efficacies when targeted to subcellular organelle such as the mitochondria. We must acknowledge that the use of nanotechnology in targeting such a complex and dynamic organelle as mitochondria can be a difficult task to achieve; however, the early advances as shown in this review is promising and encouraging. However, careful examinations of targeting properties of nanomaterials need to be critically explored to take advantage of these unique materials and their properties for subcellular targeting. Most of the reported works mainly focus on evaluation of targeting abilities of nanomaterials by fluorescence imaging. Mitochondrial association properties of such nanodelivery vehicles should be interpreted with caution. One needs to adopt multiple complementary techniques to understand the association properties of delivery vehicles with the mitochondria. Looking ahead, it is clear if carefully executed, nanotechnology based tools can provide novel alternatives for diseases where dysfunctional mitochondria are involved.

Acknowledgements: This work was supported, in whole or in part, by the Department of Defense Prostate Cancer Idea award (W81XWH-12-1-0406); American Heart Association 
National Scientist Award (14SDG18690009); National Heart, Lung, and Blood Institute of

National Institutes of Health (NIH) under award number R56HL121392; National Institute of Neurological Disorders and Stroke of NIH under award number R01NS093314 to S.D.

\section{References:}

1. Ernster L, Schatz G (1981) Mitochondria: a historical review. J Cell Biol 91:227s255s.

2. Benard G, Bellance N, James D, Parrone P, Fernandez H, Letellier T, et al. (2007) Mitochondrial bioenergetics and structural network organization. J Cell Sci 120:838848.

3. Gray MW, Burger G, Lang BF (1999) Mitochondrial evolution. Science 283:14761481.

4. Palade GE (1952) The fine structure of mitochondria. Anat Rec 114:427-451.

5. Wallace DC (1999) Mitochondrial diseases in man and mouse. Science 283:14821488.

6. Fulda S, Galluzzi L, Kroemer G (2010) Targeting mitochondria for cancer therapy. Nat Rev Drug Discov 9:447-464.

7. Perry SW, Norman JP, Barbieri J, Brown EB, Gelbard HA (2011) Mitochondrial membrane potential probes and the proton gradient: a practical usage guide. Biotechniques 50:98-115.

8. Pathak RK, Kolishetti N, Dhar S (2015) Targeted nanoparticles in mitochondrial medicine. Wiley Interdiscip Rev Nanomed Nanobiotechnol 7:315-329.

9. Kroemer G (2006) Mitochondria in cancer. Oncogene 25:4630-4632.

10. Scatena $R$ (2012) Mitochondria and cancer: a growing role in apoptosis, cancer cell metabolism and dedifferentiation. Adv Exp Med Biol 942:287-308.

11. Sullivan LB, Chandel N (2014) Mitochondria and cancer. Cancer Metab 2:4.

12. Indran IR, Tufo G, Pervaiz S, Brenner C (2011) Recent advances in apoptosis, mitochondria and drug resistance in cancer cells. BBA-Bioenergetics 1807:735-745.

13. Liberman EA, Topaly VP, Tsofina LM, Jasaitis AA, Skulachev VP (1969) Mechanism of Coupling of Oxidative Phosphorylation and the Membrane Potential of Mitochondria. Nature 222:1076-1078.

14. Skulachev VP, Antonenko YN, Cherepanov DA, Chernyak BV, Izyumov DS, Khailova LS, et al. (2010) Prevention of cardiolipin oxidation and fatty acid cycling as two antioxidant mechanisms of cationic derivatives of plastoquinone (SkQs). BBABioenergetics 1797:878-889.

15. Neuzil J, Dong L-F, Rohlena J, Truksa J, Ralph SJ (2013) Classification of mitocans, anti-cancer drugs acting on mitochondria. Mitochondrion 13:199-208.

16. Kelso GF, Porteous CM, Coulter CV, Hughes G, Porteous WK, Ledgerwood EC, et al. (2001) Selective targeting of a redox-active ubiquinone to mitochondria within cells: antioxidant and antiapoptotic properties. J Biol Chem 276:4588-4596.

17. Tauskela JS (2007) MitoQ--a mitochondria-targeted antioxidant. IDrugs 10:399-412.

18. Blanco E, Hsiao A, Ruiz-Esparza GU, Landry MG, Meric-Bernstam F, Ferrari M (2011) Molecular-targeted nanotherapies in cancer: enabling treatment specificity. Mol Oncol 5:492-503. 
19. Alexis F, Pridgen EM, Langer R, Farokhzad OC (2010) Nanoparticle technologies for cancer therapy. Handb Exp Pharmacol:55-86.

20. Pridgen EM, Alexis F, Farokhzad OC (2015) Polymeric nanoparticle drug delivery technologies for oral delivery applications. Expert Opin Drug Deliv:1-15.

21. Marrache S, Pathak RK, Dhar S (2015) Formulation and optimization of mitochondria-targeted polymeric nanoparticles. Methods Mol Biol 1265:103-112.

22. Barry NPE, Sadler PJ (2013) Challenges for Metals in Medicine: How Nanotechnology May Help To Shape the Future. ACS Nano 7:5654-5659.

23. Marrache S, Pathak RK, Darley KL, Choi JH, Zaver D, Kolishetti N, et al. (2013) Nanocarriers for tracking and treating diseases. Curr Med Chem 20:3500-3514.

24. Marrache S, Dhar S (2015) The energy blocker inside the power house: mitochondria targeted delivery of 3-bromopyruvate. Chem Sci 6:1832-1845.

25. Samuelson LE, Dukes MJ, Hunt CR, Casey JD, Bornhop DJ (2009) TSPO Targeted Dendrimer Imaging Agent: Synthesis, Characterization, and Cellular Internalization. Bioconjugate Chem 20:2082-2089.

26. Li N, Zhang C-X, Wang X-X, Zhang L, Ma X, Zhou J, et al. (2013) Development of targeting lonidamine liposomes that circumvent drug-resistant cancer by acting on mitochondrial signaling pathways. Biomaterials 34:3366-3380.

27. Marrache S, Dhar S (2012) Engineering of blended nanoparticle platform for delivery of mitochondria-acting therapeutics. Proc Natl Acad Sci U S A 109:16288-16293.

28. Biswas S, Dodwadkar NS, Sawant RR, Koshkaryev A, Torchilin VP (2011) Surface modification of liposomes with rhodamine-123-conjugated polymer results in enhanced mitochondrial targeting. J Drug Target 19:552-561.

29. Zhou J, Zhao W-Y, Ma X, Ju R-J, Li X-Y, Li N, et al. (2013) The anticancer efficacy of paclitaxel liposomes modified with mitochondrial targeting conjugate in resistant lung cancer. Biomaterials 34:3626-3638.

30. Biswas S, Dodwadkar NS, Piroyan A, Torchilin VP (2012) Surface conjugation of triphenylphosphonium to target poly(amidoamine) dendrimers to mitochondria. Biomaterials 33:4773-4782.

31. Jiang L, Li L, He X, Yi Q, He B, Cao J, et al. (2015) Overcoming drug-resistant lung cancer by paclitaxel loaded dual-functional liposomes with mitochondria targeting and pH-response. Biomaterials 52:126-139.

32. Zupančič Š, Kocbek P, Zariwala MG, Renshaw D, Gul MO, Elsaid Z, et al. (2014) Design and development of novel mitochondrial targeted nanocarriers, DQAsomes for curcumin inhalation. Mol Pharm 11:2334-2345.

33. Yamada $\mathrm{Y}$, Harashima $\mathrm{H}$ (2012) Delivery of bioactive molecules to the mitochondrial genome using a membrane-fusing, liposome-based carrier, DF-MITO-Porter. Biomaterials 33:1589-1595.

34. Yasuzaki Y, Yamada Y, Harashima H (2010) Mitochondrial matrix delivery using MITO-Porter, a liposome-based carrier that specifies fusion with mitochondrial membranes. Biochem Bioph Res Co 397:181-186.

35. Furukawa R, Yamada Y, Kawamura E, Harashima H (2015) Mitochondrial delivery of antisense RNA by MITO-Porter results in mitochondrial RNA knockdown, and has a functional impact on mitochondria. Biomaterials 57:107-115.

36. Wang XX, Li YB, Yao HJ, Ju RJ, Zhang Y, Li RJ, et al. (2011) The use of mitochondrial targeting resveratrol liposomes modified with a dequalinium polyethylene glycol-distearoylphosphatidyl ethanolamine conjugate to induce apoptosis in resistant lung cancer cells. Biomaterials 32:5673-5687. 
37. Lyrawati D, Trounson A, Cram D (2011) Expression of GFP in the mitochondrial compartment using DQAsome-mediated delivery of an artificial mini-mitochondrial genome. Pharm Res 28:2848-2862.

38. Xu Y, Szoka FC (1996) Mechanism of DNA Release from Cationic Liposome/DNA Complexes Used in Cell Transfection. Biochemistry 35:5616-5623.

39. Theodossiou TA, Sideratou Z, Katsarou ME, Tsiourvas D (2013) Mitochondrial delivery of doxorubicin by triphenylphosphonium-functionalized hyperbranched nanocarriers results in rapid and severe cytotoxicity. Pharm Res 30:2832-2842.

40. Malhi SS, Budhiraja A, Arora S, Chaudhari KR, Nepali K, Kumar R, et al. (2012) Intracellular delivery of redox cycler-doxorubicin to the mitochondria of cancer cell by folate receptor targeted mitocancerotropic liposomes. Int $J$ Pharm 432:63-74.

41. Yoong SL, Wong BS, Zhou QL, Chin CF, Li J, Venkatesan T, et al. (2014) Enhanced cytotoxicity to cancer cells by mitochondria-targeting MWCNTs containing platinum(IV) prodrug of cisplatin. Biomaterials 35:748-759.

42. Marrache S, Pathak RK, Dhar S (2014) Detouring of cisplatin to access mitochondrial genome for overcoming resistance. Proc Natl Acad Sci U S A 111:10444-10449.

43. Boddapati SV, D'Souza GGM, Erdogan S, Torchilin VP, Weissig V (2008) Organelletargeted nanocarriers: specific delivery of liposomal ceramide to mitochondria enhances its cytotoxicity in vitro and in vivo. Nano Lett 8:2559-2563.

44. Patel NR, Hatziantoniou S, Georgopoulos A, Demetzos C, Torchilin VP, Weissig V, et al. (2010) Mitochondria-targeted liposomes improve the apoptotic and cytotoxic action of sclareol. J Liposome Res 20:244-249.

45. Zhang Y, Li R-J, Ying X, Tian W, Yao H-J, Men Y, et al. (2011) Targeting therapy with mitosomal daunorubicin plus amlodipine has the potential to circumvent intrinsic resistant breast cancer. Mol Pharm 8:162-175.

46. Zhang L, Yao H-J, Yu Y, Zhang Y, Li R-J, Ju R-J, et al. (2012) Mitochondrial targeting liposomes incorporating daunorubicin and quinacrine for treatment of relapsed breast cancer arising from cancer stem cells. Biomaterials 33:565-582.

47. Mo R, Sun Q, Xue J, Li N, Li W, Zhang C, et al. (2012) Multistage pH-responsive liposomes for mitochondrial-targeted anticancer drug delivery. Adv Mater 24:36593665.

48. Sharma A, Soliman GM, Al-Hajaj N, Sharma R, Maysinger D, Kakkar A (2012) Design and evaluation of multifunctional nanocarriers for selective delivery of coenzyme Q10 to mitochondria. Biomacromolecules 13:239-252.

49. Yusuf M, Khan RA, Khan M, Ahmed B (2012) Plausible antioxidant biomechanics and anticonvulsant pharmacological activity of brain-targeted beta-carotene nanoparticles. Int J Nanomedicine 7:4311-4321.

50. Veenman L, Shandalov Y, Gavish M (2008) VDAC activation by the $18 \mathrm{kDa}$ translocator protein (TSPO), implications for apoptosis. J Bioenerg Biomembr 40:199-205.

51. Rostovtseva TK, Tan W, Colombini M (2005) On the role of VDAC in apoptosis: fact and fiction. J Bioenerg Biomembr 37:129-142.

52. Shoshan-Barmatz V, Israelson A, Brdiczka D, Sheu SS (2006) The voltagedependent anion channel (VDAC): function in intracellular signalling, cell life and cell death. Curr Pharm Des 12:2249-2270.

53. Tsujimoto Y, Shimizu S (2002) The voltage-dependent anion channel: an essential player in apoptosis. Biochimie 84:187-193. 
54. Zaid H, Abu-Hamad S, Israelson A, Nathan I, Shoshan-Barmatz V (2005) The voltage-dependent anion channel-1 modulates apoptotic cell death. Cell Death Differ 12:751-760.

55. Pastorino JG, Hoek JB (2008) Regulation of hexokinase binding to VDAC. J Bioenerg Biomembr 40:171-182.

56. Mathupala SP, Ko YH, Pedersen PL (2006) Hexokinase II: Cancer's double-edged sword acting as both facilitator and gatekeeper of malignancy when bound to mitochondria. Oncogene 25:4777-4786.

57. Chen Z, Zhang H, Lu W, Huang $P$ (2009) Role of mitochondria-associated hexokinase II in cancer cell death induced by 3-bromopyruvate. BBA-Bioenergetics 1787:553-560.

58. Mathupala SP, Ko YH, Pedersen PL (2009) Hexokinase-2 bound to mitochondria: cancer's stygian link to the "Warburg Effect" and a pivotal target for effective therapy. Semin Cancer Biol 19:17-24.

59. Zhao Y, Butler EB, Tan M (2013) Targeting cellular metabolism to improve cancer therapeutics. Cell Death Differ 4:e532.

60. Austin CJ, Kahlert J, Kassiou M, Rendina LM (2013) The translocator protein (TSPO): a novel target for cancer chemotherapy. Int J Biochem Cell Biol 45:12121216.

61. Fafalios A, Akhavan A, Parwani AV, Bies RR, McHugh KJ, Pflug BR (2009) Translocator protein blockade reduces prostate tumor growth. Clin Cancer Res 15:6177-6184.

62. Mukherjee S, Das SK (2012) Translocator protein (TSPO) in breast cancer. Curr Mol Med 12:443-457.

63. Yamada Y, Akita H, Kamiya H, Kogure K, Yamamoto T, Shinohara Y, et al. (2008) MITO-Porter: A liposome-based carrier system for delivery of macromolecules into mitochondria via membrane fusion. BBA-Biomembranes 1778:423-432.

64. Yip KW, Reed JC (2008) Bcl-2 family proteins and cancer. Oncogene 27:6398-6406.

65. Chipuk JE, Green DR (2008) How do BCL-2 proteins induce mitochondrial outer membrane permeabilization? Trends Cell Biol 18:157-164.

66. Zhang L, Ming L, Yu J (2007) BH3 mimetics to improve cancer therapy; mechanisms and examples. Drug Resist Update 10:207-217.

67. Billard C (2013) BH3 mimetics: status of the field and new developments. Mol Cancer Ther 12:1691-1700.

68. Oakes SR, Vaillant F, Lim E, Lee L, Breslin K, Feleppa F, et al. (2012) Sensitization of BCL-2-expressing breast tumors to chemotherapy by the BH3 mimetic ABT-737. Proc Natl Acad Sci U S A 109:2766-2771.

69. Chonghaile TN, Letai A (2008) Mimicking the BH3 domain to kill cancer cells. Oncogene 27:S149-S157.

70. Liu Q, Wang H-G (2012) Anti-cancer drug discovery and development. Commun Integrative Biol 5:557-565.

71. van Delft MF, Wei $A H$, Mason KD, Vandenberg CJ, Chen L, Czabotar PE, et al. (2006) The BH3 mimetic ABT-737 targets selective Bcl-2 proteins and efficiently induces apoptosis via Bak/Bax if Mcl-1 is neutralized. Cancer Cell 10:389-399.

72. Merino D, Khaw SL, Glaser SP, Anderson DJ, Belmont LD, Wong C, et al. (2012) $\mathrm{Bcl}-2, \mathrm{Bcl}-\mathrm{x}(\mathrm{L})$, and $\mathrm{Bcl}-\mathrm{w}$ are not equivalent targets of ABT-737 and navitoclax (ABT263) in lymphoid and leukemic cells. Blood 119:5807-5816. 
73. Vogler M, Dinsdale D, Dyer MJS, Cohen GM (2008) Bcl-2 inhibitors: small molecules with a big impact on cancer therapy. Cell Death Differ 16:360-367.

74. Weissig V, Lasch J, Erdos G, Meyer HW, Rowe TC, Hughes J (1998) DQAsomes: a novel potential drug and gene delivery system made from Dequalinium. Pharm Res 15:334-337.

75. Cheng SM, Pabba S, Torchilin VP, Fowle W, Kimpfler A, Schubert R, et al. (2005) Towards mitochondria-specific delivery of apoptosis-inducing agents: DQAsomal incorporated paclitaxel. J Drug Deliv Sci Tec 15:81-86.

76. Vaidya B, Vyas SP (2012) Transferrin coupled vesicular system for intracellular drug delivery for the treatment of cancer: development and characterization. J Drug Target 20:372-380.

77. D'Souza GG, Cheng SM, Boddapati SV, Horobin RW, Weissig V (2008) Nanocarrierassisted sub-cellular targeting to the site of mitochondria improves the pro-apoptotic activity of paclitaxel. J Drug Target 16:578-585.

78. Cheng S-M, Boddapati SV, D'Souza GGM, Weissig V (2007) DQAsomes as mitochondria-targeted nanocarriers for anti-cancer drugs. Nanotechnology for Cancer Therapy, ed Amiji MM (Taylor \& Franics Group, FL, USA), pp 787-802.

79. Wang $X$, Shao N, Zhang Q, Cheng $Y$ (2014) Mitochondrial targeting dendrimer allows efficient and safe gene delivery. J Mater Chem B 2:2546-2553.

80. Boddapati SV, Tongcharoensirikul P, Hanson RN, D'Souza GG, Torchilin VP, Weissig V (2005) Mitochondriotropic liposomes. J Liposome Res 15:49-58.

81. Biswas S, Dodwadkar NS, Deshpande PP, Torchilin VP (2012) Liposomes loaded with paclitaxel and modified with novel triphenylphosphonium-PEG-PE conjugate possess low toxicity, target mitochondria and demonstrate enhanced antitumor effects in vitro and in vivo. $J$ Control Release 159:393-402.

82. Breunig M, Bauer S, Goepferich A (2008) Polymers and nanoparticles: Intelligent tools for intracellular targeting? Eur J Pharm Biopharm 68:112-128.

83. Kamaly N, Xiao Z, Valencia PM, Radovic-Moreno AF, Farokhzad OC (2012) Targeted polymeric therapeutic nanoparticles: design, development and clinical translation. Chem Soc Rev 41:2971-3010.

84. Salvador-Morales C, Zhang L, Langer R, Farokhzad OC (2009) Immunocompatibility properties of lipid-polymer hybrid nanoparticles with heterogeneous surface functional groups. Biomaterials 30:2231-2240.

85. Dhar S, Kolishetti N, Lippard SJ, Farokhzad OC (2011) Targeted delivery of a cisplatin prodrug for safer and more effective prostate cancer therapy in vivo. Proc Natl Acad Sci U S A 108:1850-1855.

86. Hines DJ, Kaplan DL (2013) Poly(lactic-co-glycolic) acid-controlled-release systems: experimental and modeling insights. Crit Rev Ther Drug Carrier Syst 30:257-276.

87. Marrache S, Tundup S, Harn DA, Dhar S (2013) Ex vivo programming of dendritic cells by mitochondria-targeted nanoparticles to produce interferon-gamma for cancer immunotherapy. ACS Nano 7:7392-7402.

88. Ohta S (2006) Contribution of somatic mutations in the mitochondrial genome to the development of cancer and tolerance against anticancer drugs. Oncogene 25:47684776.

89. Wisnovsky Simon P, Wilson Justin J, Radford Robert J, Pereira Mark P, Chan Maria R, Laposa Rebecca R, et al. (2013) Targeting Mitochondrial DNA with a Platinum-Based Anticancer Agent. Chem Biol 20:1323-1328. 
90. Pathak RK, McNitt CD, Popik VV, Dhar S (2014) Copper-free click-chemistry platform to functionalize cisplatin prodrugs. Chem Eur J 20:6861-6865.

91. Feldhaeusser B, Platt SR, Marrache S, Kolishetti N, Pathak RK, Montgomery DJ, et al. (2015) Evaluation of nanoparticle delivered cisplatin in beagles. Nanoscale 7:13822-13830.

92. Marrache S, Choi JH, Tundup S, Zaver D, Harn DA, Dhar S (2013) Immune stimulating photoactive hybrid nanoparticles for metastatic breast cancer. Integr Biol 5:215-223.

93. Marrache S, Tundup S, Harn DA, Dhar S (2015) Ex vivo generation of functional immune cells by mitochondria-targeted photosensitization of cancer cells. Methods Mol Biol 1265:113-122.

94. Pathak RK, Dhar S (2015) A Nanoparticle Cocktail: Temporal Release of Predefined Drug Combinations. J Am Chem Soc 137:8324-8327.

95. Kalathil AA, Kumar A, Banik B, Ruiter TA, Pathak RK, Dhar S (2015) New formulation of old aspirin for better delivery. Chem Commun.

96. Lee Y, Gustafsson ÅB (2009) Role of apoptosis in cardiovascular disease. Apoptosis 14:536-548.

97. Kroemer G, Dallaporta B, Resche-Rigon M (1998) The mitochondrial death/life regulator in apoptosis and necrosis. Annu Rev Physiol 60:619-642.

98. Fliss H, Gattinger D (1996) Apoptosis in ischemic and reperfused rat myocardium. Circ Res 79:949-956.

99. Crow MT, Mani K, Nam Y-J, Kitsis RN (2004) The mitochondrial death pathway and cardiac myocyte apoptosis. Circ Res 95:957-970.

100. Ong S-B, Gustafsson $\AA$ B (2012) New roles for mitochondria in cell death in the reperfused myocardium. Cardiovasc Res 94:190-196.

101. Ide $\mathrm{T}$, Tsutsui $\mathrm{H}$, Kinugawa $\mathrm{S}$, Utsumi $\mathrm{H}$, Kang $\mathrm{D}$, Hattori $\mathrm{N}$, et al. (1999) Mitochondrial electron transport complex I is a potential source of oxygen free radicals in the failing myocardium. Circ Res 85:357-363.

102. Ballinger SW (2005) Mitochondrial dysfunction in cardiovascular disease. Free Radic Biol Med 38:1278-1295.

103. Epstein FH, Diaz MN, Frei B, Vita JA, Keaney Jr JF (1997) Antioxidants and atherosclerotic heart disease. N Engl J Med 337:408-416.

104. Madamanchi NR, Vendrov A, Runge MS (2005) Oxidative stress and vascular disease. Arterioscler Thromb Vasc Biol 25:29-38.

105. Oliveira HC, Cosso RG, Alberici LC, Maciel EN, Salerno AG, Dorighello GG, et al. (2005) Oxidative stress in atherosclerosis-prone mouse is due to low antioxidant capacity of mitochondria. FASEB J 19:278-280.

106. Luthi AJ, Zhang H, Kim D, Giljohann DA, Mirkin CA, Thaxton CS (2011) Tailoring of biomimetic high-density lipoprotein nanostructures changes cholesterol binding and efflux. ACS Nano 6:276-285.

107. Walters AM, Porter GA, Jr., Brookes PS (2012) Mitochondria as a drug target in ischemic heart disease and cardiomyopathy. Circ Res 111:1222-1236.

108. Ardehali H, Chen Z, Ko Y, Mejia-Alvarez R, Marban E (2004) Multiprotein complex containing succinate dehydrogenase confers mitochondrial ATP-sensitive $\mathrm{K}+$ channel activity. Proc Natl Acad Sci U S A 101:11880-11885.

109. Carvajal K, Moreno-Sanchez R (2003) Heart metabolic disturbances in cardiovascular diseases. Arch Med Res 34:89-99. 
110. Gilbert-Barness E (2002) Cardiovascular involvement in metabolic diseases. Pediatr Pathol Mol Med 21:93-136.

111. Fosslien E (2003) Review: Mitochondrial medicine--cardiomyopathy caused by defective oxidative phosphorylation. Ann Clin Lab Sci 33:371-395.

112. Rouslin W (1983) Mitochondrial complexes I, II, III, IV, and V in myocardial ischemia and autolysis. Am J Physiol 244:H743-748.

113. Asimakis GK, Conti VR (1984) Myocardial ischemia: correlation of mitochondrial adenine nucleotide and respiratory function. J Mol Cell Cardiol 16:439-447.

114. Borutaite V, Mildaziene V, Brown GC, Brand MD (1995) Control and kinetic analysis of ischemia-damaged heart mitochondria: which parts of the oxidative phosphorylation system are affected by ischemia? Biochim Biophys Acta 1272:154158.

115. Paradies G, Petrosillo G, Pistolese M, Di Venosa N, Serena D, Ruggiero FM (1999) Lipid peroxidation and alterations to oxidative metabolism in mitochondria isolated from rat heart subjected to ischemia and reperfusion. Free Radic Biol Med 27:42-50.

116. Turrens JF, Beconi M, Barilla J, Chavez UB, McCord JM (1991) Mitochondrial generation of oxygen radicals during reoxygenation of ischemic tissues. Free Radic Res Commun 12-13 Pt 2:681-689.

117. Griffiths EJ, Halestrap AP (1995) Mitochondrial non-specific pores remain closed during cardiac ischaemia, but open upon reperfusion. Biochem J 307:93-98.

118. Di Lisa F, Menabo R, Canton M, Barile M, Bernardi $P$ (2001) Opening of the mitochondrial permeability transition pore causes depletion of mitochondrial and cytosolic NAD+ and is a causative event in the death of myocytes in postischemic reperfusion of the heart. J Biol Chem 276:2571-2575.

119. Lemasters JJ, Holmuhamedov E (2006) Voltage-dependent anion channel (VDAC) as mitochondrial governator-thinking outside the box. BBA-Mol Basis Dis 1762:181190.

120. Kay L, Daneshrad Z, Saks VA, Rossi A (1997) Alteration in the control of mitochondrial respiration by outer mitochondrial membrane and creatine during heart preservation. Cardiovasc Res 34:547-556.

121. Han D, Antunes F, Canali R, Rettori D, Cadenas E (2003) Voltage-dependent anion channels control the release of the superoxide anion from mitochondria to cytosol. $J$ Biol Chem 278:5557-5563.

122. Chen L, Knowlton A (2010) Mitochondria and heart failure: new insights into an energetic problem. Minerva Cardioangiol 58:213.

123. Luo M, Anderson ME (2013) Mechanisms of altered Ca2+ handling in heart failure. Circ Res 113:690-708.

124. Suleiman MS, Halestrap AP, Griffiths EJ (2001) Mitochondria: a target for myocardial protection. Pharmacol Ther 89:29-46.

125. Granville DJ, Gottlieb RA (2003) The mitochondrial voltage-dependent anion channel (VDAC) as a therapeutic target for initiating cell death. Curr Med Chem 10:15271533.

126. Empel VPv, Bertrand AT, Hofstra L, Crijns HJ, Doevendans PA, De Windt LJ (2005) Myocyte apoptosis in heart failure. Cardiovasc Res 67:21-29.

127. Gellerich F, Trumbeckaite S, Opalka J, Seppet E, Rasmussen HN, Neuhoff C, et al. (2000) Function of the mitochondrial outer membrane as a diffusion barrier in health and diseases. Biochem Soc T28:164-169. 
128. Salnikov V, Lukyanenko Y, Frederick C, Lederer W, Lukyanenko V (2007) Probing the outer mitochondrial membrane in cardiac mitochondria with nanoparticles. Biophys J 92:1058-1071.

129. Shimizu S, Konishi A, Kodama T, Tsujimoto $Y(2000)$ BH4 domain of antiapoptotic Bcl-2 family members closes voltage-dependent anion channel and inhibits apoptotic mitochondrial changes and cell death. Proc Natl Acad Sci U S A 97:3100-3105.

130. Ono M, Sawa Y, Ryugo M, Alechine AN, Shimizu S, Sugioka R, et al. (2005) BH4 peptide derivative from $\mathrm{Bcl}-\mathrm{xL}$ attenuates ischemia/reperfusion injury thorough antiapoptotic mechanism in rat hearts. Eur J Cardiothorac Surg 27:117-121.

131. Gincel D, Zaid H, Shoshan-Barmatz V (2001) Calcium binding and translocation by the voltage-dependent anion channel: a possible regulatory mechanism in mitochondrial function. Biochem J 358:147-155.

132. Correa F, Soto V, Zazueta C (2007) Mitochondrial permeability transition relevance for apoptotic triggering in the post-ischemic heart. Int J Biochem Cell Biol 39:787-798.

133. Nahon E, Israelson A, Abu-Hamad S, Shoshan-Barmatz V (2005) Fluoxetine (Prozac) interaction with the mitochondrial voltage-dependent anion channel and protection against apoptotic cell death. FEBS Lett 579:5105-5110.

134. Hu J, Dong L, Outten CE (2008) The redox environment in the mitochondrial intermembrane space is maintained separately from the cytosol and matrix. $J$ Biol Chem 283:29126-29134.

135. Rone MB, Fan J, Papadopoulos V (2009) Cholesterol transport in steroid biosynthesis: role of protein-protein interactions and implications in disease states. BBA-Mol Cell Biol L 1791:646-658.

136. Miller WL (2007) Steroidogenic acute regulatory protein (StAR), a novel mitochondrial cholesterol transporter. BBA-Mol Cell Biol L 1771:663-676.

137. Ren S, Hylemon P, Marques D, Hall E, Redford K, Gil G, et al. (2004) Effect of increasing the expression of cholesterol transporters (StAR, MLN64, and SCP-2) on bile acid synthesis. J Lipid Res 45:2123-2131.

138. Korytowski W, Wawak K, Pabisz P, Schmitt JC, Girotti AW (2014) Macrophage mitochondrial damage from StAR transport of 7-hydroperoxycholesterol: Implications for oxidative stress-impaired reverse cholesterol transport. FEBS Lett 588:65-70.

139. Kim CK, Kim T, Choi IY, Soh M, Kim D, Kim YJ, et al. (2012) Ceria nanoparticles that can protect against ischemic stroke. Angew Chem Int Ed Engl 124:11201-11205.

140. Pramanik D, Campbell NR, Das S, Gupta S, Chenna V, Bisht S, et al. (2012) A composite polymer nanoparticle overcomes multidrug resistance and ameliorates doxorubicin-associated cardiomyopathy. Oncotarget 3:640.

141. Park S, Yoon J, Bae S, Park M, Kang C, Ke Q, et al. (2014) Therapeutic use of $\mathrm{H} 2 \mathrm{O} 2$-responsive anti-oxidant polymer nanoparticles for doxorubicin-induced cardiomyopathy. Biomaterials 35:5944-5953.

142. Schubert D, Dargusch R, Raitano J, Chan S-W (2006) Cerium and yttrium oxide nanoparticles are neuroprotective. Biochem Bioph Res Co 342:86-91.

143. Niu J, Azfer A, Rogers LM, Wang X, Kolattukudy PE (2007) Cardioprotective effects of cerium oxide nanoparticles in a transgenic murine model of cardiomyopathy. Cardiovasc Res 73:549-559.

144. Houtkooper R, Vaz F (2008) Cardiolipin, the heart of mitochondrial metabolism. Cell Mol Life Sci 65:2493-2506. 
145. Sparagna GC, Chicco AJ, Murphy RC, Bristow MR, Johnson CA, Rees ML, et al. (2007) Loss of cardiac tetralinoleoyl cardiolipin in human and experimental heart failure. J Lipid Res 48:1559-1570.

146. Petrosillo G, Di Venosa N, Pistolese M, Casanova G, Tiravanti E, Colantuono G, et al. (2006) Protective effect of melatonin against mitochondrial dysfunction associated with cardiac ischemia-reperfusion: role of cardiolipin. FASEB J 20:269-276.

147. Nomura K, Imai H, Koumura T, Kobayashi T, Nakagawa Y (2000) Mitochondrial phospholipid hydroperoxide glutathione peroxidase inhibits the release of cytochrome c from mitochondria by suppressing the peroxidation of cardiolipin in hypoglycaemiainduced apoptosis. Biochem J 351:183-193.

148. Philippe P, Joanne EP, Elinor JG, Andrew PH (2011) The role of oxidized cytochrome $\mathrm{C}$ in regulating mitochondrial reactive oxygen species production and its perturbation in ischaemia. Biochem $J$ 436:493-505.

149. Binder CJ (2012) Naturally occurring IgM antibodies to oxidation-specific epitopes. Adv Exp Med Biol 750:2-13.

150. Rosca MG, Vazquez EJ, Kerner J, Parland W, Chandler MP, Stanley W, et al. (2008) Cardiac mitochondria in heart failure: decrease in respirasomes and oxidative phosphorylation. Cardiovasc Res 80:30-39.

151. Grover GJ, Atwal KS, Sleph PG, Wang F-L, Monshizadegan H, Monticello T, et al. (2004) Excessive ATP hydrolysis in ischemic myocardium by mitochondrial F1F0ATPase: effect of selective pharmacological inhibition of mitochondrial ATPase hydrolase activity. Am J Physiol Heart Circ Physiol 287:H1747-H1755.

152. Grover GJ, Malm J (2008) Pharmacological profile of the selective mitochondrial F1F0 ATP hydrolase inhibitor BMS-199264 in myocardial ischemia. Cardiovasc Ther 26:287-296.

153. Hausenloy DJ, Boston- Griffiths E, Yellon D (2012) Cyclosporin A and cardioprotection: from investigative tool to therapeutic agent. $\mathrm{Br} J$ Pharmacol 165:1235-1245.

154. Ikeda G (2013) Nanoparticle-mediated targeting of cyclosporine A to mitochondria in reperfused myocardium enhances cardioprotection from ischemia-reperfusion injury. Circulation 128:A15712.

155. Lim SY, Hausenloy DJ, Arjun S, Price AN, Davidson SM, Lythgoe MF, et al. (2011) Mitochondrial cyclophilin- $D$ as a potential therapeutic target for post- myocardial infarction heart failure. J Cell Mol Med 15:2443-2451.

156. Fancelli D, Abate A, Amici R, Bernardi P, Ballarini M, Cappa A, et al. (2014) Cinnamic anilides as new mitochondrial permeability transition pore inhibitors endowed with ischemia-reperfusion injury protective effect in vivo. $J$ Med Chem 57:5333-5347.

157. Yin Q, Pei Z, Wang H, Zhao Y (2014) Cyclosporine A-nanoparticles enhance the therapeutic benefit of adipose tissue-derived stem cell transplantation in a swine myocardial infarction model. Int $J$ Nanomedicine 9:17-26.

158. Ayer A, Macdonald P, Stocker R (2015) CoQ10 in Heart Failure and Ischemic Heart Disease. Annu Rev Nutr 35.

159. Gvozdjákova A, Takahashi T, Singh R, De Meester F, Wilson DW, Crane FL (2013) New roles of coenzyme Q10 in cardiovascular diseases, discovered by a single group. World Heart J 5:159. 
160. Langsjoen PH, Langsjoen PH, Folkers K (1990) Long-term efficacy and safety of coenzyme Q 10 therapy for idiopathic dilated cardiomyopathy. Am J Cardiol 65:521523.

161. Rosenfeldt F, Marasco S, Lyon W, Wowk M, Sheeran F, Bailey M, et al. (2005) Coenzyme Q 10 therapy before cardiac surgery improves mitochondrial function and in vitro contractility of myocardial tissue. J Thorac Cardiovasc Surg 129:25-32.

162. Swarnakar NK, Jain AK, Singh RP, Godugu C, Das M, Jain S (2011) Oral bioavailability, therapeutic efficacy and reactive oxygen species scavenging properties of coenzyme Q10-loaded polymeric nanoparticles. Biomaterials 32:68606874.

163. Yamada Y, Nakamura K, Abe J, Hyodo M, Haga S, Ozaki M, et al. (2015) Mitochondrial delivery of Coenzyme $Q 10$ via systemic administration using a MITOPorter prevents ischemia/reperfusion injury in the mouse liver. $J$ Control Release 213:86-95.

164. Amorim Cde M, Couto AG, Netz DJ, de Freitas RA, Bresolin TM (2010) Antioxidant idebenone-loaded nanoparticles based on chitosan and $\mathrm{N}$-carboxymethylchitosan. Nanomedicine 6:745-752.

165. Ghule A, Mandpe L, Pokharkar V, Jadhav S, Bodhankar S (2014) Cardioprotective effect of idebenone nanoparticles in doxorubicin induced cardiomyopathy in rats: assessment of myocardial performance, haemapoietic parameters and immunological changes. J Pharm Sci Pharmacol 1:26-39.

166. Lowes DA, Thottakam BM, Webster NR, Murphy MP, Galley HF (2008) The mitochondria-targeted antioxidant MitoQ protects against organ damage in a lipopolysaccharide-peptidoglycan model of sepsis. Free Radic Biol Med 45:15591565.

167. Adlam VJ, Harrison JC, Porteous CM, James AM, Smith RA, Murphy MP, et al. (2005) Targeting an antioxidant to mitochondria decreases cardiac ischemiareperfusion injury. FASEB J 19:1088-1095.

168. Graham D, Huynh NN, Hamilton CA, Beattie E, Smith RA, Cochemé HM, et al. (2009) Mitochondria-targeted antioxidant MitoQ10 improves endothelial function and attenuates cardiac hypertrophy. Hypertension 54:322-328.

169. Rodriguez-Cuenca S, Cochemé HM, Logan A, Abakumova I, Prime TA, Rose C, et al. (2010) Consequences of long-term oral administration of the mitochondriatargeted antioxidant MitoQ to wild-type mice. Free Radic Biol Med 48:161-172.

170. Chacko B, Reily C, Srivastava A, Johnson M, Ye Y, Ulasova E, et al. (2010) Prevention of diabetic nephropathy in Ins2+/Minus SignAkitaJ mice by the mitochondria-targeted therapy MitoQ. Biochem J 432:9-19.

171. Chacko BK, Srivastava A, Johnson MS, Benavides GA, Chang MJ, Ye Y, et al. (2011) Mitochondria- targeted ubiquinone (MitoQ) decreases ethanol- dependent micro and macro hepatosteatosis. Hepatology 54:153-163.

172. Dare AJ, Bolton EA, Pettigrew GJ, Bradley JA, Saeb-Parsy K, Murphy MP (2015) Protection against renal ischemia-reperfusion injury in vivo by the mitochondria targeted antioxidant MitoQ. Redox Biol 5:163-168.

173. Mercer JR, Yu E, Figg N, Cheng K-K, Prime TA, Griffin JL, et al. (2012) The mitochondria-targeted antioxidant MitoQ decreases features of the metabolic syndrome in ATM+/-/ApoE-/-mice. Free Radic Biol Med 52:841-849.

174. Yu E, Calvert PA, Mercer JR, Harrison J, Baker L, Figg NL, et al. (2013) Mitochondrial DNA damage can promote atherosclerosis independently of reactive 
oxygen species through effects on smooth muscle cells and monocytes and correlates with higher-risk plaques in humans. Circulation 128:702-712.

175. Jia Z, Wang X, Qin Y, Xue L, Jiang P, Meng Y, et al. (2013) Coronary heart disease is associated with a mutation in mitochondrial tRNA. Hum Mol Genet 22:4064-4073.

176. Ghezzi D, Baruffini E, Haack TB, Invernizzi F, Melchionda L, Dallabona C, et al. (2012) Mutations of the mitochondrial-tRNA modifier MTO1 cause hypertrophic cardiomyopathy and lactic acidosis. Am J Hum Genet 90:1079-1087.

177. Zaragoza MV, Brandon MC, Diegoli M, Arbustini E, Wallace DC (2011) Mitochondrial cardiomyopathies: how to identify candidate pathogenic mutations by mitochondrial DNA sequencing, MITOMASTER and phylogeny. Eur J Hum Genet 19:200-207.

178. Dai D-F, Santana LF, Vermulst M, Tomazela DM, Emond MJ, MacCoss MJ, et al. (2009) Overexpression of catalase targeted to mitochondria attenuates murine cardiac aging. Circulation 119:2789-2797.

179. Nair N, Gongora E (2014) MicroRNAs as therapeutic targets in cardiomyopathies: myth or reality? Biomol Concepts 5:439-448.

180. Damiano MG, Mutharasan RK, Tripathy S, McMahon KM, Thaxton CS (2013) Templated high density lipoprotein nanoparticles as potential therapies and for molecular delivery. Adv Drug Deliv Rev 65:649-662.

181. Marrache S, Dhar S (2013) Biodegradable synthetic high-density lipoprotein nanoparticles for atherosclerosis. Proc Natl Acad Sci U S A 110:9445-9450.

182. Holt IJ, Harding AE, Morgan-Hughes JA (1988) Deletions of muscle mitochondrial DNA in patients with mitochondrial myopathies. Nature 331:717-719.

183. Holt IJ, Harding AE, Petty RK, Morgan-Hughes JA (1990) A new mitochondrial disease associated with mitochondrial DNA heteroplasmy. Am J Hum Genet 46:428433.

184. Schon EA, Bonilla E, DiMauro S (1997) Mitochondrial DNA mutations and pathogenesis. J Bioenerg Biomembr 29:131-149.

185. Coleman M, Blass JP (1985) Autism and lactic acidosis. J Autism Dev Disord 15:1-8.

186. Lombard J (1998) Autism: a mitochondrial disorder? Med Hypotheses 50:497-500.

187. Giulivi C, Zhang Y, Omanska-Klusek A, et al. (2010) Mltochondrial dysfunction in autism. JAMA 304:2389-2396.

188. Tang G, Gutierrez Rios P, Kuo SH, Akman HO, Rosoklija G, Tanji K, et al. (2013) Mitochondrial abnormalities in temporal lobe of autistic brain. Neurobiol Dis 54:349361.

189. Chauhan A, Gu F, Essa MM, Wegiel J, Kaur K, Brown WT, et al. (2011) Brain regionspecific deficit in mitochondrial electron transport chain complexes in children with autism. J Neurochem 117:209-220.

190. Rose S, Melnyk S, Pavliv O, Bai S, Nick TG, Frye RE, et al. (2012) Evidence of oxidative damage and inflammation associated with low glutathione redox status in the autism brain. Transl Psychiatry 2:e134.

191. Rahimov F, Kunkel LM (2013) The cell biology of disease: cellular and molecular mechanisms underlying muscular dystrophy. J Cell Biol 201:499-510.

192. Kelly-Worden M, Thomas E (2014) Mitochondrial dysfunction in duchenne muscular dystrophy. Open J Endocr Metab Dis Vol.04No.08:8.

193. Akopova OV, Kolchynskayia LY, Nosar VY, Smyrnov AN, Malisheva MK, Man'kovskaia YN, et al. (2011) The effect of permeability transition pore opening on reactive oxygen species production in rat brain mitochondria. Ukr Biokhim Zh (1999) 83:46-55. 
194. Onopiuk M, Brutkowski W, Wierzbicka K, Wojciechowska S, Szczepanowska J, Fronk J, et al. (2009) Mutation in dystrophin-encoding gene affects energy metabolism in mouse myoblasts. Biochem Biophys Res Commun 386:463-466.

195. Millay DP, Sargent MA, Osinska H, Baines CP, Barton ER, Vuagniaux G, et al. (2008) Genetic and pharmacologic inhibition of mitochondrial-dependent necrosis attenuates muscular dystrophy. Nat Med 14:442-447.

196. Falzarano MS, Passarelli C, Ferlini A (2014) Nanoparticle delivery of antisense oligonucleotides and their application in the exon skipping strategy for Duchenne muscular dystrophy. Nucleic Acid Ther 24:87-100.

197. Jarver P, Coursindel T, Andaloussi SEL, Godfrey C, Wood MJA, Gait MJ (2012) Peptide-mediated cell and in vivo delivery of antisense oligonucleotides and siRNA. Mol Ther Nucleic Acids 1:e27.

198. Bibee KP, Cheng YJ, Ching JK, Marsh JN, Li AJ, Keeling RM, et al. (2014) Rapamycin nanoparticles target defective autophagy in muscular dystrophy to enhance both strength and cardiac function. FASEB J 28:2047-2061.

199. Folbergrova J, Kunz WS (2012) Mitochondrial dysfunction in epilepsy. Mitochondrion 12:35-40.

200. Waldbaum S, Patel M (2010) Mitochondria, oxidative stress, and temporal lobe epilepsy. Epilepsy Res 88:23-45.

201. Kunz WS, Kudin AP, Vielhaber S, Blumcke I, Zuschratter W, Schramm J, et al. (2000) Mitochondrial complex I deficiency in the epileptic focus of patients with temporal lobe epilepsy. Ann Neurol 48:766-773.

202. Waldbaum S, Liang LP, Patel M (2010) Persistent impairment of mitochondrial and tissue redox status during lithium-pilocarpine-induced epileptogenesis. J Neurochem 115:1172-1182.

203. Jabir NR, Tabrez S, Firoz CK, Zaidi SK, Baeesa SS, Gan SH, et al. (2015) A synopsis of nano-technological approaches toward anti-epilepsy therapy: present and future research implications. Curr Drug Metab 16:336-345.

204. Lee J-H, Jung S-W, Kim I-S, Jeong Y-I, Kim Y-H, Kim S-H (2003) Polymeric nanoparticle composed of fatty acids and poly(ethylene glycol) as a drug carrier. Int $J$ Pharm 251:23-32.

205. Fresta M, Cavallaro G, Giammona G, Wehrli E, Puglisi G (1996) Preparation and characterization of polyethyl-2-cyanoacrylate nanocapsules containing antiepileptic drugs. Biomaterials 17:751-758.

206. Hamidi M, Azadi A, Mohamadi-Samani S, Rafiei P, Ashrafi H (2012) ValproateLoaded hydrogel nanoparticles: Preparation and characterization. J Appl Poly Sci 124:4686-4693.

207. Ueda M, Kreuter J (1997) Optimization of the preparation of loperamide-loaded poly (L-lactide) nanoparticles by high pressure emulsification-solvent evaporation. $J$ Microencapsul 14:593-605.

208. Ying X, Wang Y, Liang J, Yue J, Xu C, Lu L, et al. (2014) Angiopep-conjugated electro-responsive hydrogel nanoparticles: therapeutic potential for epilepsy. Angew Chem Int Ed Engl 53:12436-12440.

209. Yokoyama H, Mori N, Osonoe K, Ishida S, Kumashiro H (1992) Anticonvulsant effect of liposome-entrapped superoxide dismutase in amygdaloid-kindled rats. Brain Res 572:273-275. 
210. Kizelsztein P, Ovadia H, Garbuzenko O, Sigal A, Barenholz Y (2009) Pegylated nanoliposomes remote-loaded with the antioxidant tempamine ameliorate experimental autoimmune encephalomyelitis. J Neuroimmunol 213:20-25.

211. Shi P, Gal J, Kwinter DM, Liu X, Zhu H (2010) Mitochondrial dysfunction in amyotrophic lateral sclerosis. Biochimica et biophysica acta 1802:45-51.

212. Bunton-Stasyshyn RKA, Saccon RA, Fratta P, Fisher EMC (2015) SOD1 function and its implications for amyotrophic lateral sclerosis pathology: new and renascent themes. Neuroscientist 21:519-529.

213. Eisen A (2009) Amyotrophic lateral sclerosis: A 40-year personal perspective. J Clin Neurosci 16:505-512.

214. Reddy M, Wu L, Kou W, Ghorpade A, Labhasetwar V (2008) Superoxide dismutaseloaded PLGA nanoparticles protect cultured human neurons under oxidative stress. Appl Biochem Biotechnol 151:565-577.

215. Ali SS, Hardt JI, Dugan LL (2008) SOD Activity of carboxyfullerenes predicts their neuroprotective efficacy: a structure-activity study. Nanomedicine 4:283-294.

216. Cho Y, Shi R, Borgens RB, Ivanisevic A (2008) Functionalized mesoporous silica nanoparticle-based drug delivery system to rescue acrolein-mediated cell death. Nanomedicine 3:507-519.

217. Hong S, Choi I, Lee S, Yang YI, Kang T, Yi J (2009) Sensitive and colorimetric detection of the structural evolution of superoxide dismutase with gold nanoparticles. Anal Chem 81:1378-1382.

218. McFarland R, Taylor RW, Turnbull DM (2010) A neurological perspective on mitochondrial disease. Lancet Neurol 9:829-840.

219. Holmes D (New IVF techniques put mitochondrial diseases in focus. Lancet Neurol 13:28-29.

220. Su B, Wang X, Zheng L, Perry G, Smith MA, Zhu X (2010) Abnormal mitochondrial dynamics and neurodegenerative diseases. BBA-Mol Basis Dis 1802:135-142.

221. Venna N (2004) Mitochondrial neurological diseases: a clinician's perspective. Neurol India 52:305-306.

222. Zhu J, Wang KZQ, Chu CT (2013) After the banquet: Mitochondrial biogenesis, mitophagy, and cell survival. Autophagy 9:1663-1676. 


\section{Nanotechnology Mediated Targeting of Mitochondria}

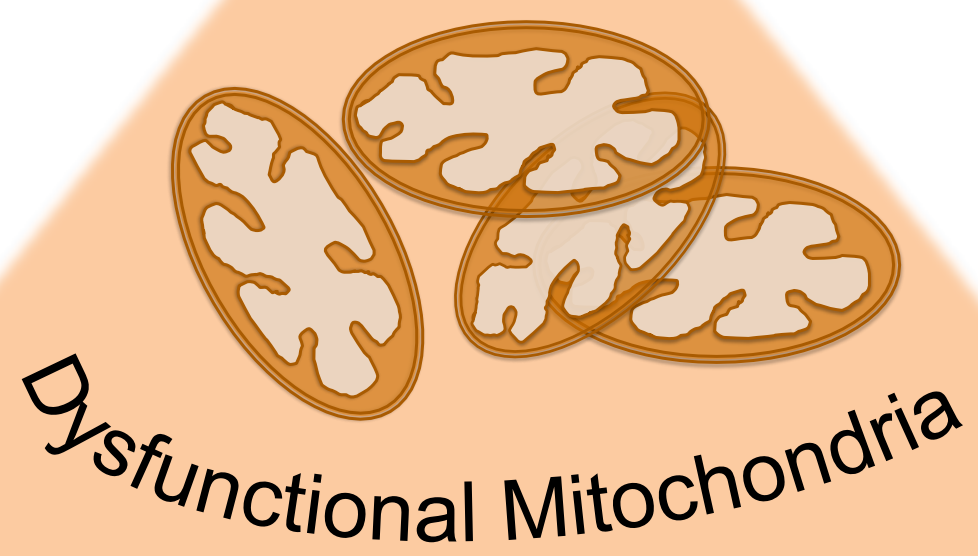

范 Cardiovascular Diseases

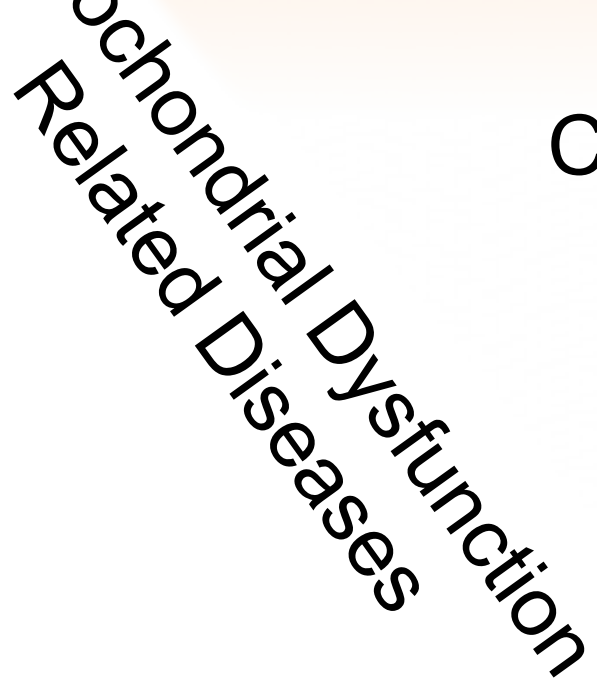

Cancer

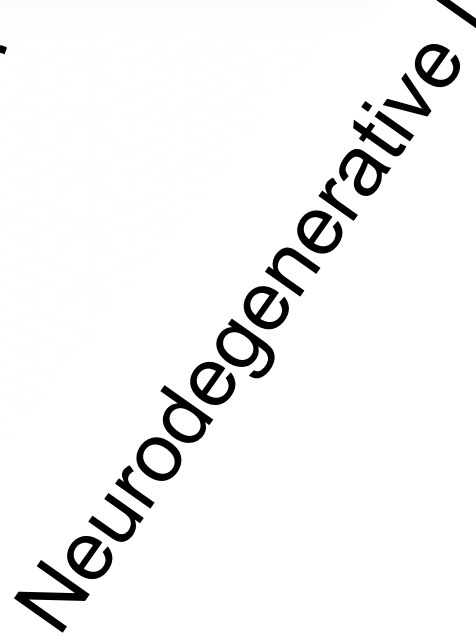

